\title{
Mid-infrared supercontinuum generation in chalcogenide glass fibers: a brief review
}

\author{
Yingying Wang ${ }^{1,2,3}$ and Shixun Dai ${ }^{1,2,3^{*}}$
}

\author{
* Correspondence: daishixun@nbu. \\ edu.cn \\ ${ }^{1}$ Laboratory of Infrared Material and \\ Devices, The Research Institute of \\ Advanced Technologies, Ningbo \\ University, Ningbo 315211, China \\ ${ }^{2}$ Key Laboratory of Photoelectric \\ Materials and Devices of Zhejiang \\ Province, Ningbo 315211, China \\ Full list of author information is \\ available at the end of the article
}

\begin{abstract}
Chalcogenide (ChG) glasses have the characteristics of a wide transparency window (over $20 \mu \mathrm{m}$ ) and high optical nonlinearity (up to $10^{3}$ times greater than that of silica glasses), exhibiting great advantages over silica and other soft glasses in optical property at mid-infrared (MIR) wavelength range. These make them excellent candidates for MIR supercontinuum (SC) generation. Over the past decades, great progress has been made in MIR SC generation based on ChG fibers in terms of spectral extension and output power improvement. In this paper, we introduce briefly the properties of ChG glasses and fibers including transmission, nonlinearity, and dispersion, etc. Recent progress in MIR SC generation based on ChG fibers is reviewed from the perspective of pump schemes. We also present novel ChG fibers such as As-free, Te-based, and chalcohalide fibers, which have been explored and employed as nonlinear fibers to achieve broadband SC generation. Moreover, the potential applications of MIR SC sources based on ChG fibers are discussed.
\end{abstract}

Keywords: Chalcogenide glass fiber, Supercontinuum generation, Mid-infrared, Nonlinear optics

\section{Introduction}

Supercontinuum (SC) generation in nonlinear media originates from the interaction of ultrashort pulses and the dispersion and nonlinear effects, such as self-phase modulation (SPM), four wave mixing, stimulated Raman scattering (SRS), soliton selffrequency shift, etc. [1-3]. It is a process in which narrow band pump pulses with high peak power are broadened continuously in the spectral domain. SC Sources have been studied extensively in various nonlinear media (including solids, liquids, gases) since1970, when it was first reported by Alfano et al. in BK7 glass pumped by a modelocked Nd: glass laser [4].

SC sources with spatial coherence, broad bandwidth, and high brightness have received considerable attention due to their significant potential in various applications, such as sensing [5-7], biomedical science [8], spectral tissue imaging $[9,10]$, and optical coherence tomography [11, 12]. During the past two decades, many researchers have been devoted to extending the SC spectral range from visible and near-infrared (NIR) to ultraviolet and mid-infrared (MIR) even far-infrared (FIR). In particular, the MIR spectral region is regarded as an important topic because most molecules exhibit

(c) The Author(s). 2021 Open Access This article is licensed under a Creative Commons Attribution 4.0 International License, which permits use, sharing, adaptation, distribution and reproduction in any medium or format, as long as you give appropriate credit to the original author(s) and the source, provide a link to the Creative Commons licence, and indicate if changes were made. The images or other third party material in this article are included in the article's Creative Commons licence, unless indicated otherwise in a credit line to the material. If material is not included in the article's Creative Commons licence and your intended use is not permitted by statutory regulation or exceeds the permitted use, you will need to obtain permission directly from the copyright holder. To view a copy of this licence, visit http://creativecommons.org/licenses/by/4.0/. 
fundamental vibrational absorption bands in this region $[5,9,13]$, leaving distinctive spectral fingerprints which are critical for applications, such as biomedical science, sensing, and defense and security. However, SC sources generated in silica fibers are limited in the spectral evolution into MIR due to the strong material absorption beyond $2.5 \mu \mathrm{m}$.

Various soft-glass fibers made of fluoride [14-18], tellurite [19, 20], and chalcogenide (ChG) glasses [21-25] have been used to generate MIR SCs, and numerous achievements have been accomplished. Fluoride and tellurite are both transparent in the wavelength range of lower than $5.5 \mu \mathrm{m}$ and thus may cannot be used in relatively long wavelengths. By contrast, ChG glasses have comparatively wider transparency window (over $20 \mu \mathrm{m}$ ) [26, 27] and higher optical nonlinearity (up to a thousand times greater than that of silica glasses) [28], making them excellent candidates for MIR SC generation. To date, an ultrabroad SC generation spanning from 2 to $16 \mu \mathrm{m}$ has been achieved in a Te-based ChG fiber [25], and a high SC output power reaching $1.13 \mathrm{~W}$ has also been realized in a cascaded $\mathrm{As}_{2} \mathrm{~S}_{3}$ fiber [29].

In this paper, properties of ChG glasses and fibers including transmission, nonlinearity, and dispersion, etc., are introduced firstly. Then we review recent progress in MIR SC generation based on ChG fibers from the perspective of pump schemes, including pumped by fiber lasers, solid-state lasers, and cascaded SC sources, and novelty ChG fibers such as As-free, Te-based, and chalcohalide $(\mathrm{ChH})$ fibers, which have been used as nonlinear media for broadband SC generation. Finally, the applications of MIR SC sources based on ChG fibers in spectroscopy and other fields are discussed.

\section{ChG glass fiber}

ChG glasses, known for more than half a century as infrared (IR) optical materials, are a non-oxide class of glasses that are mainly composed by one or more chalcogen elements in group VIA of the periodic table, such as sulfur (S), selenium (Se), and tellurium (Te), in combination with some other metalloid elements (arsenic (As), antimony $(\mathrm{Sb})$, germanium $(\mathrm{Ge})$, etc) [30]. Bulk ChG glasses are usually prepared using highpurity elements by melt-quenching [31, 32], as well as microwave radiation [33, 34], and chemical vapor deposition techniques [35]. Figure 1 shows bulk samples of three typical ChG glasses.

Several significant features of ChG glasses have made them attractive in the MIR range. A highly important property of ChG glasses is their broad IR transparency range, which extends the long wavelength cut-off edge from 12 to $20 \mu \mathrm{m}$ depending on the

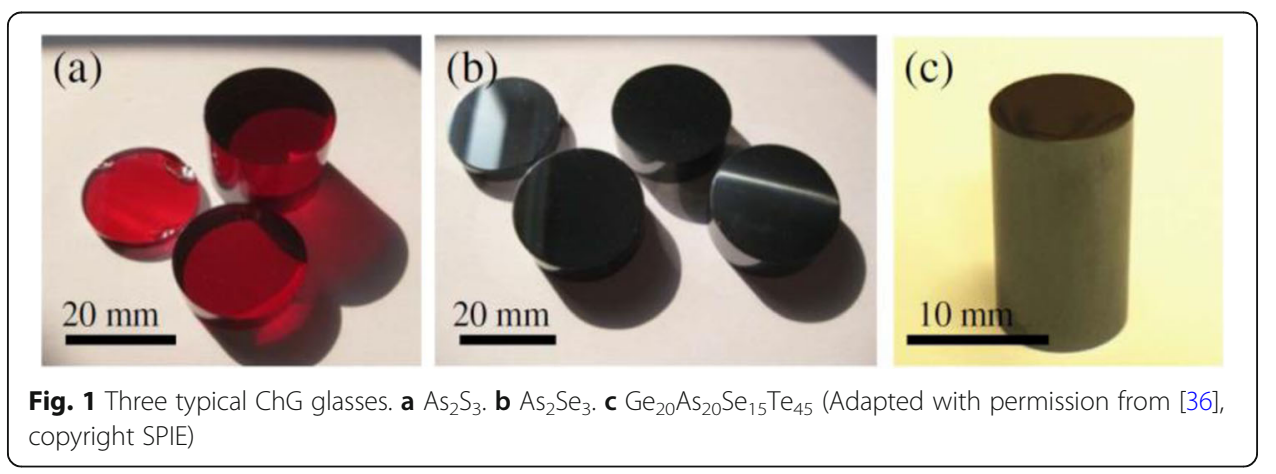


mass of anionic elements present in the ChG glasses (viz. S, Se, and Te, as shown in Fig. 2) [26, 27], implying that they are the unique medium which can extend the SC spectrum to MIR even FIR region. ChG glasses have high third-order optical nonlinearity up to a thousand times greater than that of silica glasses, attributed to their high refractive indices $(2.0 \sim 3.5)[28,37]$. Besides, they also exhibit fast nonlinear response $(<$ $100 \mathrm{fs}$ ), and adjustable glass composition. These properties make ChG glasses excellent candidates for MIR SC generation.

The zero material dispersion wavelength (ZMDW) of $\mathrm{ChG}$ glasses is always located at long wavelengths. For example, the $\mathrm{ZMDW}$ of $\mathrm{As}_{2} \mathrm{Se}_{3}$ glass is $\sim 8 \mu \mathrm{m}$, and that of $\mathrm{As}_{2} \mathrm{~S}_{3}$ is $5 \mu \mathrm{m}$. Depending partly on material dispersion, the zero dispersion wavelengths (ZDWs) of ChG step-index fibers, which are usually made via the double crucible [38,39], or pre-formed via rod-in-tube [40-42] or extrusion methods [43, 44], also lie in long wavelengths, resulting in a large normal and steep dispersion at the relatively shorter wavelengths.

The ability to tailor the fiber dispersion profile is an underlying theme across all glass and fiber designs. The use of tapered fiber (TF) or microstructured optical fiber (MOF) always provides primary flexibility in light confinement, nonlinearity enhancement, and dispersion control [45-49]. By tapering a fiber into a smaller core diameter, the fiber waveguide dispersion can be engineered, so that the total dispersion can be controlled precisely from normal to zero or even anomalous region. As can be seen from Fig. 3, the ZDW can be shifted from 5.35 to $1.88 \mu \mathrm{m}$ in a $\mathrm{As}_{2} \mathrm{Se}_{3}$ TF when the fiber core diameter is reduced from 40 to $3 \mu \mathrm{m}$. Meanwhile, the fiber nonlinearity will increase dramatically by one order of magnitude for the decreased effective mode area. Besides the fiber core size, MOFs can engineer the waveguide dispersion by changing their structural parameters. Among them, two key geometrical parameters of MOFs are the diameter of air hole and the pitch between each two holes, which have a great influence on fiber dispersion. However, the preform fabrication methods of ChG MOFs, such as stack and draw [51, 52], casting [53-55], and mechanical drilling [56, 57], are complicated and technically difficult. Even a size error on the submicron level of the air hole diameter or the pitch during the MOF manufacturing process will cause the difference

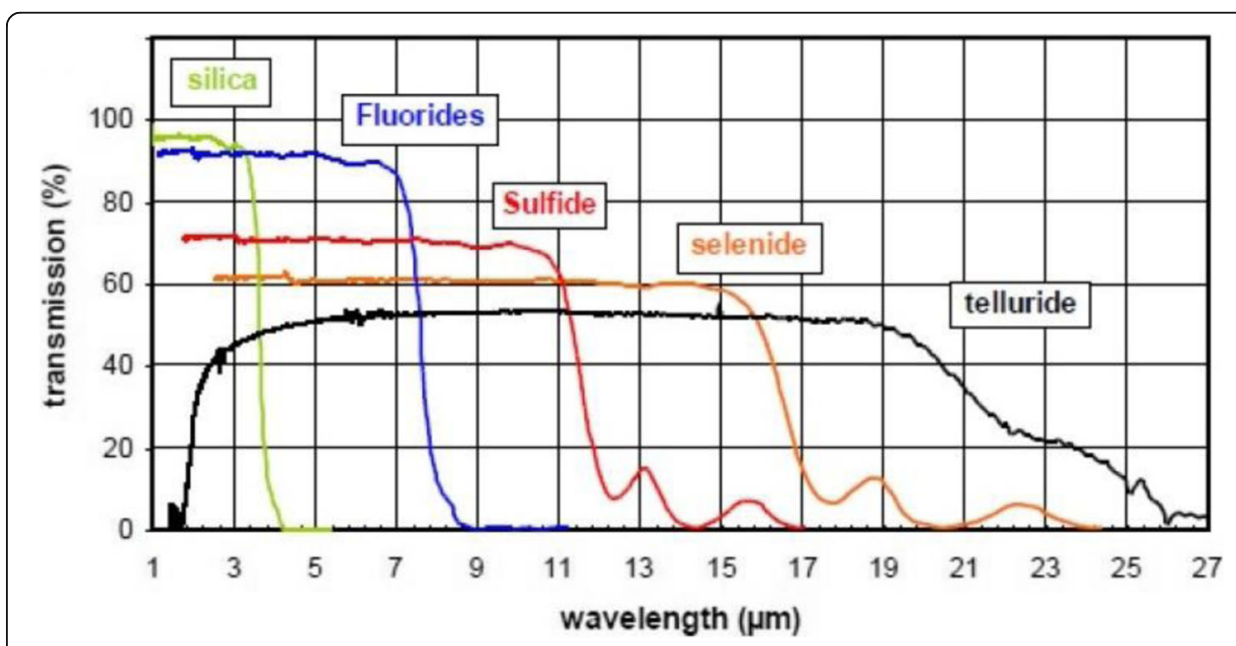

Fig. 2 Transmittance spectra of silica, fluorides, sulfide, selenide and telluride bulk glasses. (Adapted from [27]) 


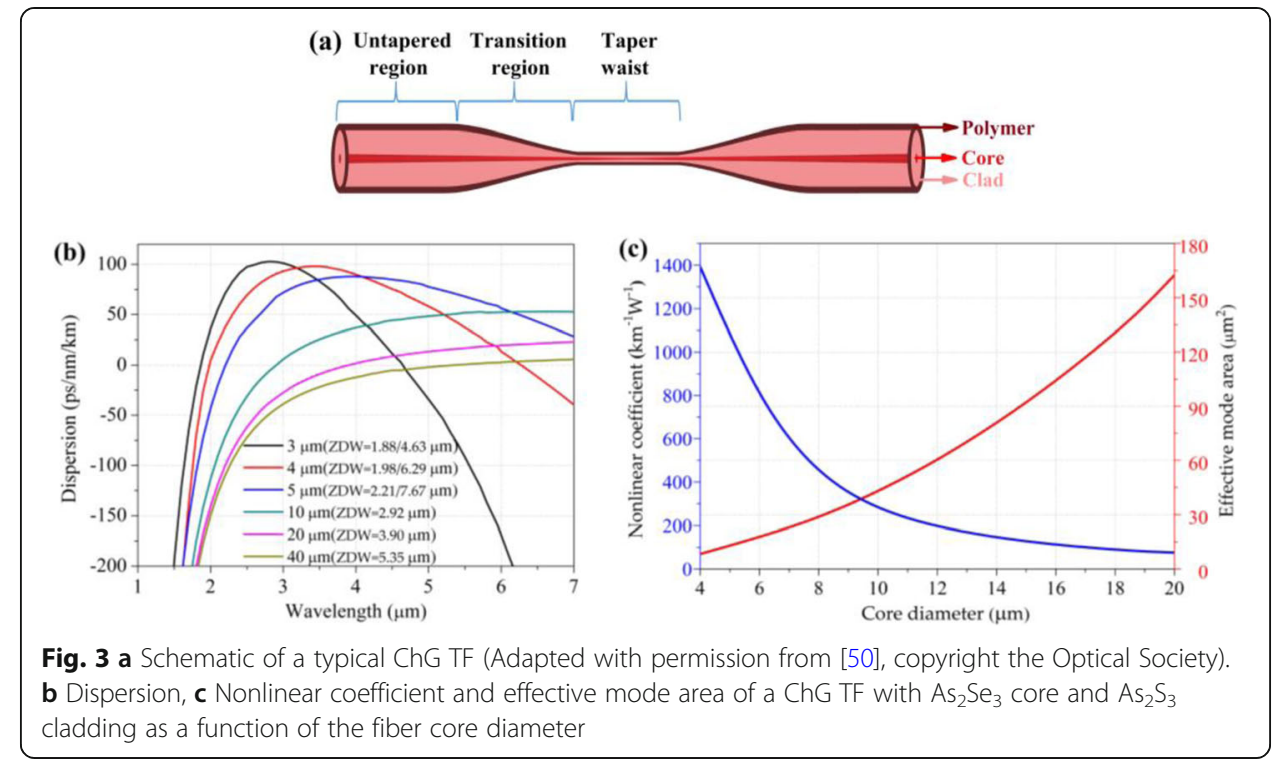

of ZDW, as can be seen in Fig. 4. In addition, the MOF transmission loss will increase due to microdeformations when the core size decreases.

\section{MIR SC generation in ChG fibers}

MIR SC generation based on ChG fiber was firstly reported from an As-Se fiber in 2005 [58]. Since then, SC sources from ChG fibers with large bandwidth, high brightness, and high degree of coherence have attracted wide attention and become a research focus. In this section, we discuss the MIR SC generation in ChG fibers in terms of pump scheme by fiber lasers, solid-state lasers, and cascaded SC sources.

\section{Pumping ChG fibers by fiber lasers}

Using fiber lasers as pump sources to excite nonlinear fibers and produce SC sources exhibits a compact structural system and stable operating performance. Meanwhile, it is suitable for the construction of all-fiber SC sources. Benefiting from the development of optical communication devices, $1.5 \mu \mathrm{m}$ waveband fiber lasers have been used as pump sources in early research of SC generation from ChG fibers.

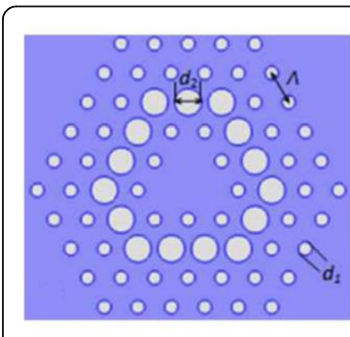

(a)

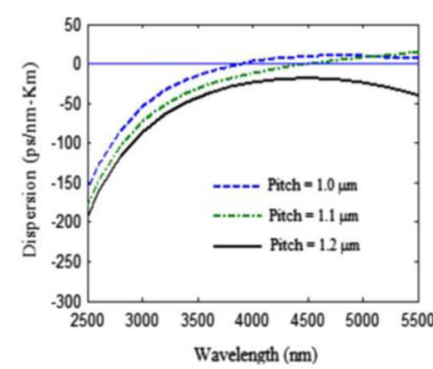

(b)

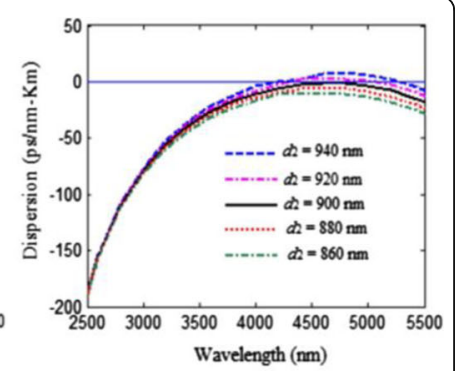

(c)

Fig. 4 a Cross-section of a triangular-core MOF. Dispersion curves as a function of wavelength varying $\mathbf{b}$ the pitch and $\mathbf{c}$ the air hole diameter (Adapted with permission from [22], copyright Elsevier B. V) 
In 2005, Wei et al. demonstrated an SC generation in a 1.5-m-long $\mathrm{As}_{2} \mathrm{~S}_{3}$ singlemode step-index fiber pumped in the normal dispersion regime [59]. A passively mode-locked Er-doped fiber laser operating at $1.5 \mu \mathrm{m}$, far away from the fiber ZDW of $4.9 \mu \mathrm{m}$, was used as the pump source with a pulse duration of $100 \mathrm{fs}$ and a repetition rate of $20 \mathrm{MHz}$, as shown in Fig. 5a. With the maximum input pump power of 16.4 $\mathrm{mW}$, the output spectrum was broadened with a $-15 \mathrm{~dB}$ bandwidth of $310 \mathrm{~nm}$ (Fig. $5 b)$. Although the spectral width of the SC generation was not wide, the observed spectral broadening was very attractive and it confirmed the possibility of ChG fibers for MIR SC generation.

The development of optical fiber devices at $2 \mu \mathrm{m}$ is relatively slow compared with optical communication devices. With the progress of them, $2 \mu \mathrm{m}$ fiber lasers and amplifiers have also been employed to pump ChG fibers. A multistage master oscillator power amplifier (MOPA) was used to shift the fiber laser wavelength to a relatively longer wavelength region, which is shown in Fig. 6a, where a $1.55 \mu \mathrm{m}$ seed laser is amplified by $\mathrm{Er} / \mathrm{Yb}$ co-doped amplifier and transformed into $2 \mu \mathrm{m}$ by nonlinear frequency conversion. Then it is boosted by a TDFA to increase the pump power dramatically. Propagation in a HNLF continues to shift the pump wavelength into $2.4 \mu \mathrm{m}$. Adopting a pumping scheme like this, Gattass et al. achieved an SC with a wide spectral coverage

(a)

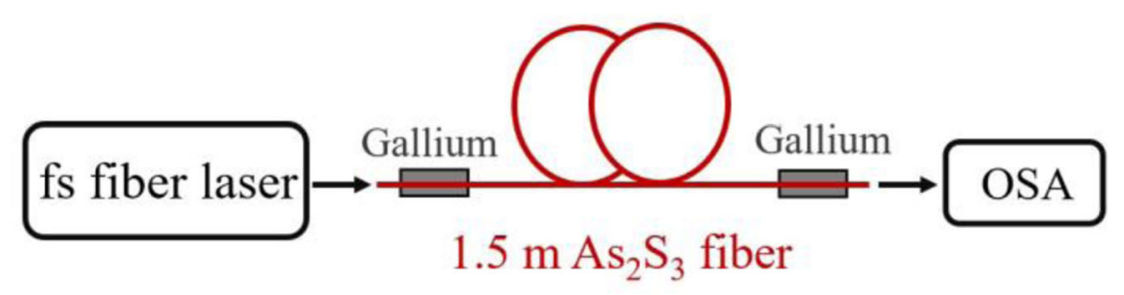

(b)

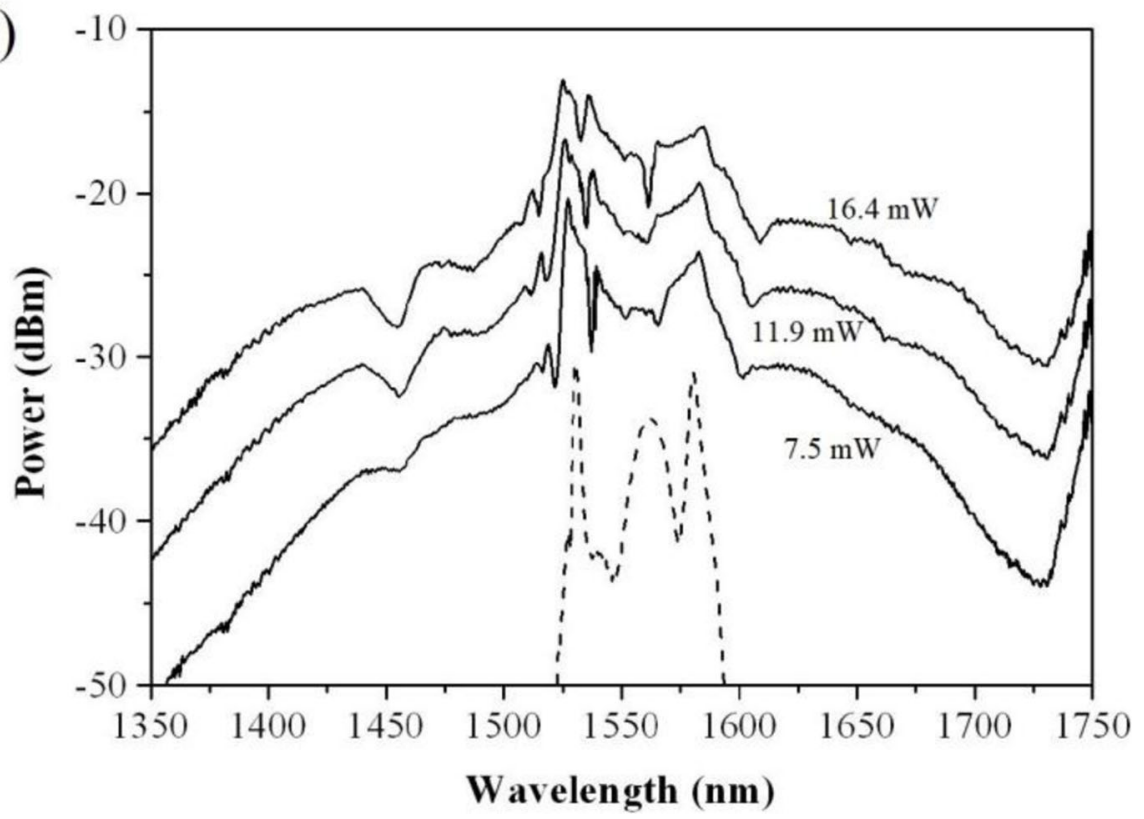

Fig. 5 a Experimental setup for $\mathrm{SC}$ generation in an $\mathrm{As}_{2} \mathrm{~S}_{3}$ step-index fiber pumped by a Er-doped fiber laser. b SC sources generated from an $\mathrm{As}_{2} \mathrm{~S}_{3}$ step-index fiber (Adapted with permission from [59], copyright the Optical Society) 
(a)
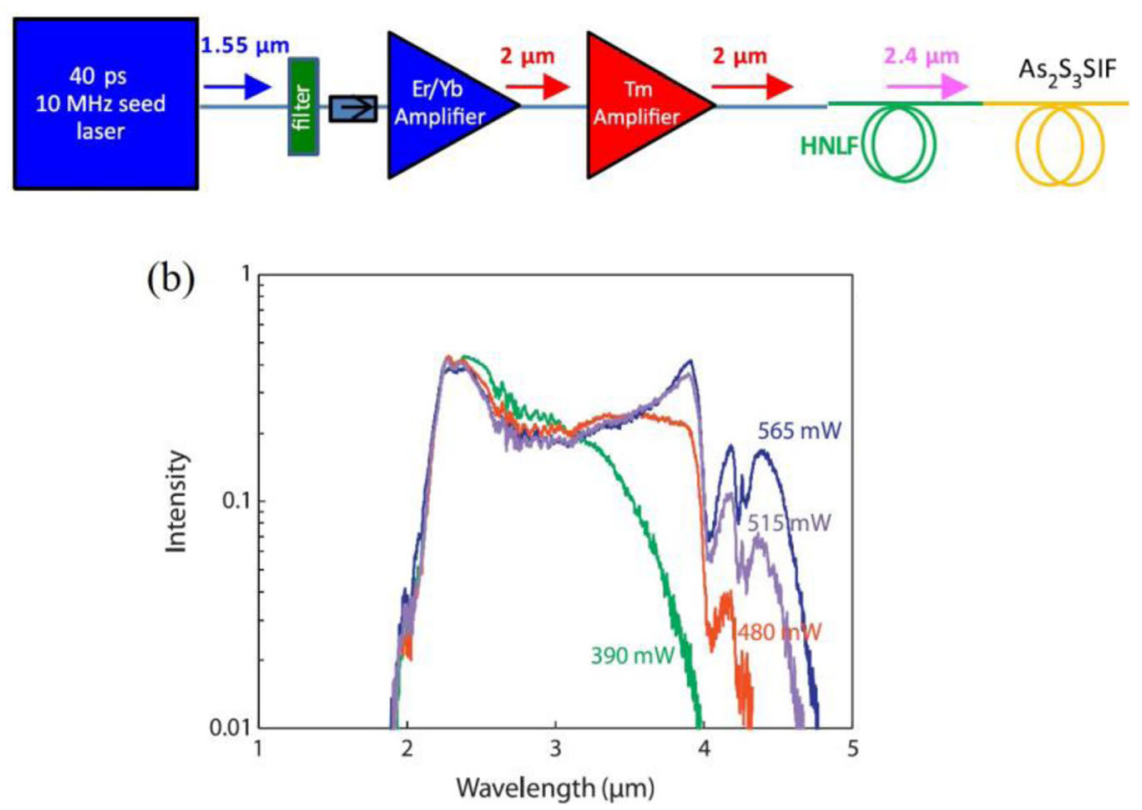

Fig. 6 a A typical schematic of SC generation based on a MOPA pump system. $\mathbf{b}$ SC generation in a 2-mlong step-index $\mathrm{As}_{2} \mathrm{~S}_{3}$ fiber with a wide spectral coverage of 1.9-4.8 $\mu \mathrm{m}$ and a high average output power of $565 \mathrm{~mW}$ (Adapted with permission from [60], copyright Elsevier B. V)

of $1.9-4.8 \mu \mathrm{m}$ and a high average output power of $565 \mathrm{~mW}$ in a 2-m-long step-index $\mathrm{As}_{2} \mathrm{~S}_{3}$ fiber as shown in Fig. 6b [60], although the pump wavelength was also located at the normal dispersion region. This can be attributed to the longer operation wavelength of $2.4 \mu \mathrm{m}$ than $1.5 \mu \mathrm{m}$ and higher pump power of $1.4 \mathrm{~W}$ entering the ChG fiber.

However, as we can see, broadband MIR SC generation is hardly achieved in ChG step-index fibers pumped in the normal dispersion regime by a short-wavelength fiber laser. This is because during the process of spectral extension in the normal dispersion regime, the nonlinear effects of SPM, SRS and optical wave break, play important roles $[2,59]$. These nonlinear effects are always limited by the pump peak power and fiber dispersion slopes, inevitably impairing the spectral broadening.

In general, efficient and broadband SC generation can be obtained by pumping in the anomalous dispersion regime close to the ZDW of the fiber [21, 41, 56, 61]. In this case, the SC generation in fibers pumped in the anomalous dispersion regime with a high peak power is dominated by soliton dynamics such as soliton fission and soliton self-frequency shift in the long wavelengths and dispersion waves in the short wavelength [62-66]. However, depending partly on the material dispersion, the ZDWs of ChG step-index fibers are usually located at long wavelengths $(>5 \mu \mathrm{m})$. Therefore, it is necessary to match the ZDWs of ChG fibers with the operation wavelengths of commercial fiber lasers by MOFs or TFs.

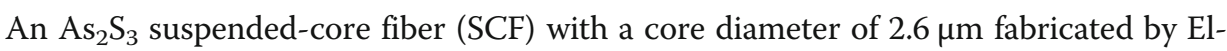
Amraoui et al. [67], had a ZDW of $2.2 \mu \mathrm{m}$, appearing strongly shifted toward shorter wavelengths by comparison with the ZDW of the bulk glass. When injecting $400 \mathrm{fs}$ pulses at $1557 \mathrm{~nm}$ with a repetition rate of $16.75 \mathrm{MHz}$ and peak power of $5.6 \mathrm{~kW}$ into a 68-cm-long $\mathrm{As}_{2} \mathrm{~S}_{3} \mathrm{SCF}$, soliton dynamics cannot be excited in the normal dispersion region, leading to a broadened spectrum spanning only from 1 to $2.6 \mu \mathrm{m}$. In 2011, 
Hudson et al. tapered an $\mathrm{As}_{2} \mathrm{~S}_{3}$ fiber into a taper waist diameter of $1.3 \mu \mathrm{m}$, exhibiting a ZDW around 1.4 $\mu \mathrm{m}$ [62]. The pump pulses with a duration of $250 \mathrm{fs}$ at $38.6 \mathrm{MHz}$ repetition rate were generated from an erbium-fiber-based mode-locked laser. An SC generation spanning from 970 to $1990 \mathrm{~nm}$ was achieved from the TF by using only 77 pJ pump pulse energy ( $3 \mathrm{~mW}$ average power). Rudy et al. adopted a Tm-doped fiber laser and amplifier system as the pump source, which produced sub-100-fs pulses with a center wavelength of $2.04 \mu \mathrm{m}$ at $75 \mathrm{MHz}$ repetition rate [68]. An $\mathrm{As}_{2} \mathrm{~S}_{3}$ fiber with a core/clad diameter of 7/160 $\mu \mathrm{m}$ was tapered to a diameter of $2 \mu \mathrm{m}$ to shift the dispersion to the anomalous region at pump operation wavelength. A 1 to $3.7 \mu \mathrm{m} \mathrm{SC}$ was obtained from this TF under a pulse energy of $300 \mathrm{pJ}$.

From above cases we can see that SC sources can be generated from MOFs/TFs pumped by pulses with low energy thanks to their extremely high nonlinear coefficient, but problems are brought that the generated SC sources are still narrow in spectral range or low in output power. This is because fiber lasers used as pump sources in these experiments operate with short wavelength, low average or peak pump power, hindering the SC broadening process. Therefore, it is more advantageous to extend the SC spectrum to longer wavelength range on condition that the pump laser works in the MIR region with high power.

Ultrafast MIR fiber lasers operating around $3 \mu \mathrm{m}$ have been demonstrated which were obtained from ion-doped fluoride fibers [69]. By co-doping $\mathrm{Ho}^{3+}$ and $\mathrm{Pr}^{3+}$ into a 4-m-long $\mathrm{ZrF}_{4}-\mathrm{BaF}_{2}-\mathrm{LaF}_{3}-\mathrm{AlF}_{3}-\mathrm{NaF}$ (ZBLAN) fiber, a stable pulse train at $2.9 \mu \mathrm{m}$ was achieved with a duration of $230 \mathrm{fs}$ and an average power of $140 \mathrm{~mW}$ at $42 \mathrm{MHz}$ repetition rate, as shown in Fig. 7. By injecting such a pump laser in to a $\mathrm{As}_{2} \mathrm{Se}_{3} \mathrm{TF}$, a broadband SC generation covering 1.8-9.5 $\mu \mathrm{m}$ with an average power of more than $30 \mathrm{~mW}$ was achieved although the TF showed an all-normal dispersion in the whole wavelength range [70].

It is noted that a free-space method including the lens coupling and butt-coupling is employed in most experiments to direct the pump light from silica to ChG fibers, resulting in a coupling loss always $>2 \mathrm{~dB}$ mainly from the Fresnel reflection and mode filed mismatch. Inevitably, this not only causes an unnecessary consumption of pump power and reduces the system efficiency, but also aggravates the instability of the SC sources. To realize a robust SC generation, permanent fusion splicing of $\mathrm{ChG}$ and silica fibers is required, which is a great technology challenge due to the significant
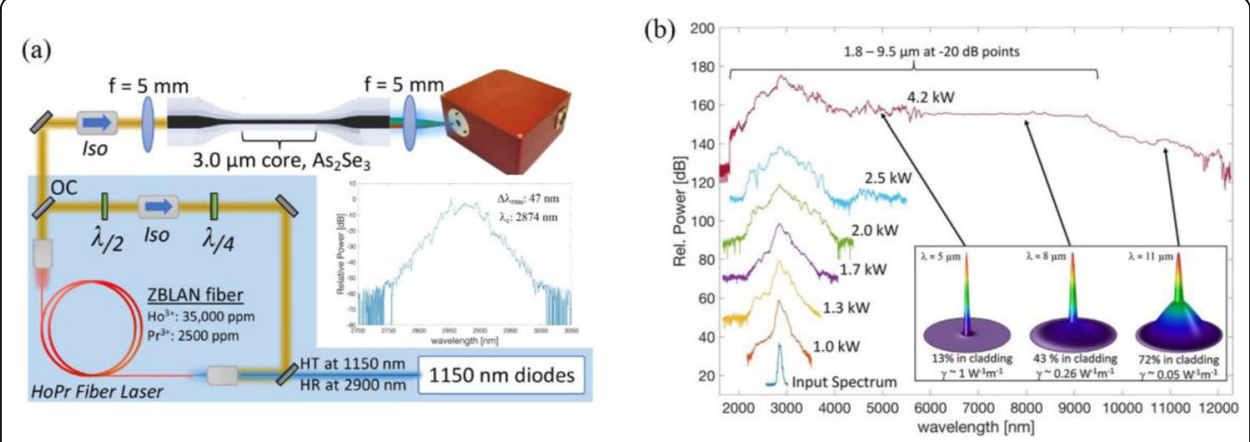

Fig. 7 a Experimental setup for the ultrashort MIR laser and the subsequent SC generation. The inset is the optical spectrum of the pump pulses. $\mathbf{b} \mathrm{SC}$ generation in the $\mathrm{As}_{2} \mathrm{Se}_{3}$ TF pumped by increasing peak power (Adapted with permission from [70], copyright the Optical Society) 
differences in glass transition temperatures and thermal expansion coefficients between ChG and silica fibers. Even so, a robust and repeatable fusion splicing technique was achieved by Thapa et al. in 2015 to join silica fiber and $\mathrm{As}_{2} \mathrm{~S}_{3}$ ChG fiber using a filament splicer (Fig. 8a), exhibiting a low splice loss of less than $0.5 \mathrm{~dB}$ measured at $2.5 \mu \mathrm{m}$ [71]. Adopting an experimental setup similar to Fig. 6a, which produced picosecond pulses at $2.5 \mu \mathrm{m}$ with a repetition rate of $2.5 \mathrm{MHz}$ and an average power of 550 $\mathrm{mW}$, an SC spanning from 2 to $4.5 \mu \mathrm{m}$ with an output power of $211 \mathrm{~mW}$ was generated from a 2-m-long $\mathrm{As}_{2} \mathrm{~S}_{3}$ fiber in such an all-fiber system, as shown in Fig. 8b, presenting a major development toward compact, robust, and high-power MIR SC sources.

\section{Pumping ChG fibers by solid-state lasers}

Pumping with solid-state lasers has been proven an effective method to produce broadband SC generation in nonlinear fibers. Solid-state lasers based on optical parametric process such as optical parametric amplifier (OPA) and optical parametric oscillator (OPO) have been developed in recent years, which can produce ultrashort laser pulses with tunable wavelength from NIR to MIR and high peak power in the order of megawatt, providing a flexible pump source for SC generation.

An ultrabroad MIR SC spanning from 1.4 to $13.3 \mu \mathrm{m}$ was generated experimentally in an 85-mm-long step-index fiber made of $\mathrm{As}_{2} \mathrm{Se}_{3}$ core and $\mathrm{Ge}_{10} \mathrm{As}_{23.4} \mathrm{Se}_{66.6}$ clad when launched $\sim 100 \mathrm{fs}$ pulses with a repetition rate of $1 \mathrm{kHz}$ from an OPA [61]. The pump peak power into the fiber was estimated to be $2.29 \mathrm{MW}$, and the pump wavelength of $6.3 \mu \mathrm{m}$ was located in the anomalous dispersion regime, just above the fiber ZDW of $5.83 \mu \mathrm{m}$. Figure 9 shows the setup used for SC generation. This was the first time that an SC source with a spectral width of $>10 \mu \mathrm{m}$ was achieved in nonlinear fibers, and transparent atmospheric windows of 3-5 $\mu \mathrm{m}$ and $8-13 \mu \mathrm{m}$, and the significant part of the fingerprint region of molecular vibrational resonances were covered, representing a breakthrough in broadband MIR SC source research.

Researchers subsequently focused on the enhancement of SC broadening. ChG fibers with short fiber length, small core diameter, high nonlinearity, and optimized pump conditions were designed and used to generate SC spectra with good performance. For example, an As-Se fiber with a short length of only $3 \mathrm{~cm}$ and a ZDW of $5.5 \mu \mathrm{m}$ was pumped by pulses at $9.8 \mu \mathrm{m}$ with $170 \mathrm{fs}$ pulse duration and $1 \mathrm{kHz}$ repetition rate produced from a difference frequency generation. When the peak power was $2.89 \mathrm{MW}$, an $\mathrm{SC}$ generation spanning from 2 to $15.1 \mu \mathrm{m}$ was obtained [72].
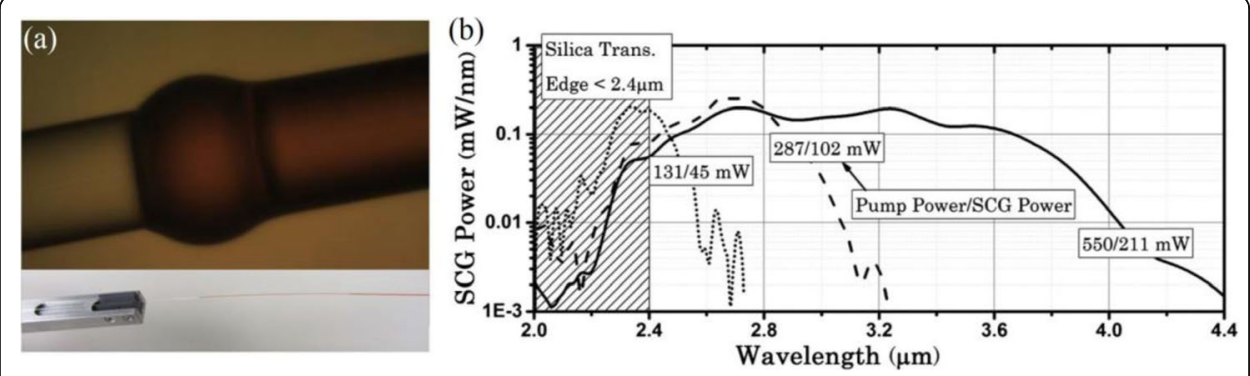

Fig. 8 a Micrograph of the fusion splice between silica and ChG fibers. b SC generation in the $\mathrm{As}_{2} \mathrm{~S}_{3}$ fiber pumped by pulsed laser at $2.5 \mu \mathrm{m}$ (Adapted with permission from [71], copyright the Optical Society) 


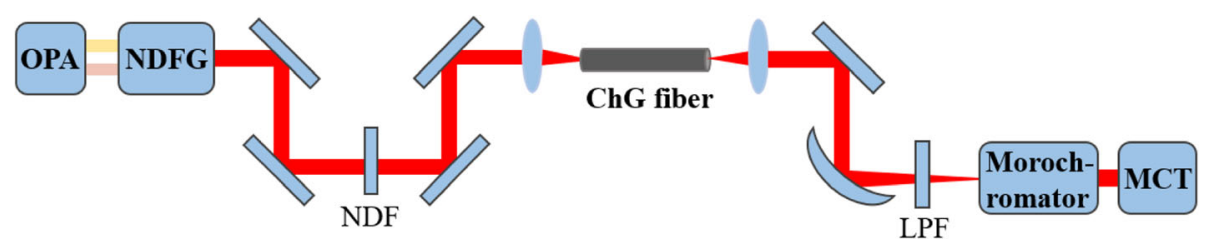

Fig. 9 Setup for SC generation in the ChG fiber pumped by an OPA. LPF, long-pass filter; NDF, neutral density filter; NDFG, noncollinear difference frequency generation

Thanks to the simple structure and the ease of operation, solid-state lasers are increasingly employed to pump ChG fibers for SC generation. Meanwhile, MOFs/TFs with extremely high nonlinearities can also be pumped in the anomalous dispersion range even though their ZDWs are situated at long wavelengths.

An SC generation in an 18-cm-long $\mathrm{As}_{38} \mathrm{Se}_{62}$ SCF with a core diameter of $4.5 \mu \mathrm{m}$ and ZDW of $3.5 \mu \mathrm{m}$ was presented pumped at different wavelengths with $320 \mathrm{fs}$ pulses from an OPA [73]. When the pump wavelength was shifted from 3.5 to $4.7 \mu \mathrm{m}$, the solitonic long wavelength edge moved to longer wavelengths, and accordingly the dispersive waves was shifted to shorter wavelengths. Consequently, the broadest spectrum spanning from 1.7 to $7.5 \mu \mathrm{m}$ and the largest output power of $15.6 \mathrm{~mW}$ was obtained when pumped at $4.4 \mu \mathrm{m}$. Moreover, the SC broadening was also investigated in a 12-cm-long As-S TF by optimizing its transition region length [50]. When the diameter of the transition region changes slowly with a relatively longer transition length, there is always accompanied by a smaller number of higher-order modes, and thus higher transmission efficiency of light, resulting in a higher output power and a larger spectral broadening from the TF. A $1.4-7.2 \mu \mathrm{m}$ SC generation with an average power of $1.06 \mathrm{~mW}$ was finally achieved from the TF with a transition region length of $10 \mathrm{~mm}$ pumped by an OPA with $150 \mathrm{fs}$ pulse duration and $1 \mathrm{kHz}$ repetition rate at $3.25 \mu \mathrm{m}$.

In addition, tapered MOFs with large-mode-area can also be used for SC generation, thus a high coupling efficiency and damage threshold for the pump power injected to the fiber end facet will be obtained, while the tapered waist offers strong nonlinearity and anomalous dispersion at the pump wavelength. Moreover, the MOF structure can ensure single-mode propagation, which improves the beam quality and reduces losses in the taper due to higher-order mode stripping. Peterson et al. tapered a $15.1 \mu \mathrm{m}$ core $\mathrm{Ge}_{10} \mathrm{As}_{22} \mathrm{Se}_{68}$ photonic crystal fiber (PCF) with a large mode area into a core diameter of $5.9 \mu \mathrm{m}$ at the taper waist [74]. The higher-order modes excited in the large-core fiber were stripped during the propagation in the transition region. As can be seen in Fig. 10, by using an OPA source with $250 \mathrm{fs}$ pulse duration and $21 \mathrm{MHz}$ repetition rate at $4 \mu \mathrm{m}$, the broadest bandwidth from 1 to $11.5 \mu \mathrm{m}$ with an average output power of $35.4 \mathrm{~mW}$, and the highest output power of $57.3 \mathrm{~mW}$ with a spectral bandwidth spanning from 1 to $8 \mu \mathrm{m}$ were generated in the tapered PCFs, which were optimized in the fiber length before and after the taper. Besides, relatively shorter taper waists, higher pitch-to-hole ratio, and shorter fiber length before the taper are all advantageous for extending SC to longer wavelengths.

It has been indicated in a large number of researches that ultrabroad MIR SC generation can be obtained by using solid-state lasers to pump ChG fibers. However, the free-space characteristic of the pump source causes that the light can only be injected into fibers though coupling lens, making the whole system unable to achieve the all- 


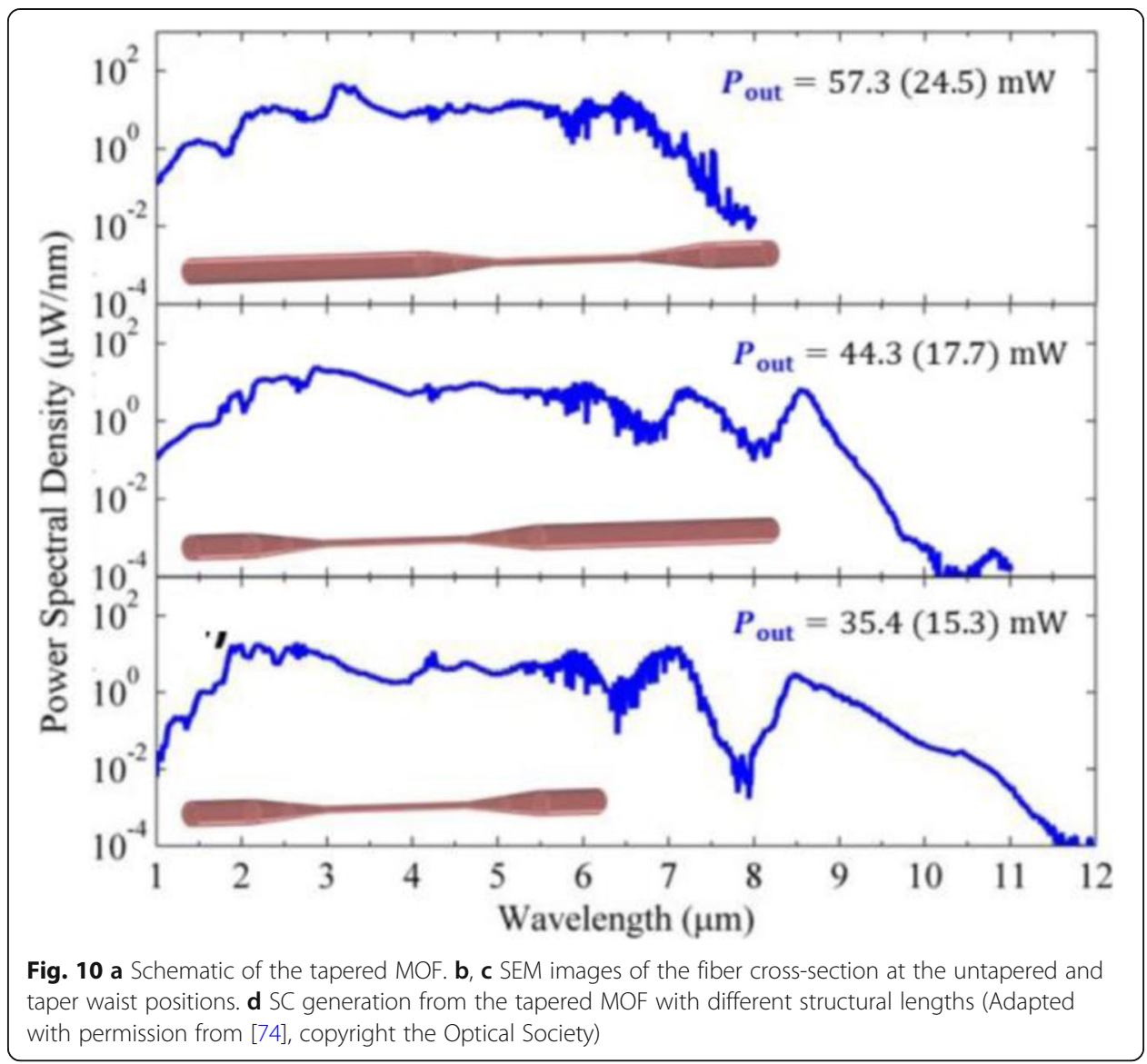

fiber construction, compact structure, and good stability for a fiber-based SC sources. In addition, solid-state lasers have disadvantages like bigger sizes, heavier weight and higher cost, which also limits the development of the SC sources generated by this scheme to practical applications.

\section{Pumping ChG fibers by cascaded SC sources}

Cascading SC approach has been demonstrated where a fiber-based SC is used to pump another fiber to further extend the SC spectral coverage, which was numerically proposed by Kubat et al. in 2014 firstly and shown in Fig. 11 [75]. This cascading approach is mainly based on the SC spectrum that contains many solitons with ultrashort pulses and high peak powers in the long wavelength range from the first-stage fiber with anomalous dispersion. As long as the second-stage fiber has a ZDW below the SC long wavelength edge, the solitons can continue to redshift in the second-stage fiber when two fibers are cascading, which can further lead to a wide SC generation. Therefore, the choice of these fibers is particularly important because it can affect the dynamics and efficiency of SC generation. Generally, fluoride fibers are always chosen as the firststage fiber in the cascading scheme because of the following excellent properties: 1) high damage threshold; 2) generating SC sources with $>3.5 \mu \mathrm{m}$ long wavelength edge extending above the ZDW of typical step-index fluoride fibers around $1.5 \mu \mathrm{m}$; 3) high output power of up to $30 \mathrm{~W}[18]$. 


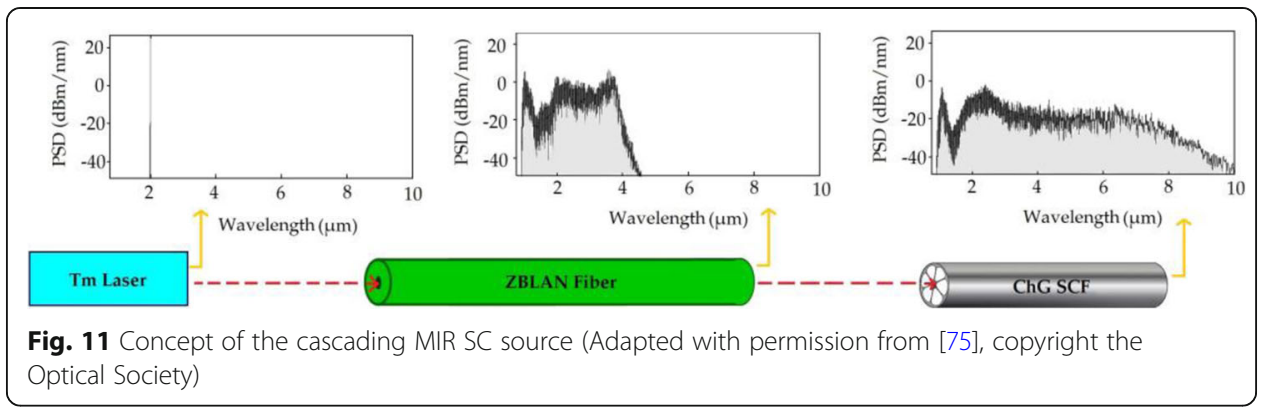

Subsequently, this concept has been proved to be feasible by many experimental results [29, 76-80]. In [29], a MOPA pump laser with a repetition rate of $600 \mathrm{kHz}$ shown in Fig. 12a was used to increase the average pump power to several tens of watts from the TDFA. An all-fiber structure was also constructed to not only avoid the power loss caused by free-space system, improving the SC source efficiency, but also reduce the configuration complexity, making it more suitable for field applications. Eventually, the maximum SC output power from the 7-m-long ZBLAN fiber (first-stage fiber) was increased to $5 \mathrm{~W}$ with a spectrum broadening to $4.2 \mu \mathrm{m}$ (Fig. 12b). The SC generated from the 4-m-long $\mathrm{As}_{2} \mathrm{~S}_{3}$ fiber (second-stage fiber) was extended from 2 to $6.5 \mu \mathrm{m}$, possessing a high output power reaching $1.13 \mathrm{~W}$ (Fig. 12(c)).

To further broaden the $\mathrm{SC}$ spectrum range, $\mathrm{As}_{2} \mathrm{Se}_{3}$ fibers are always adopted as the third-stage fiber thanks to their longer ZDW and MIR transmission edge. By the threestage cascading scheme, Martinez et al. realized a broadband SC generation utilizing a MOPA to pump the cascading ZBLAN, $\mathrm{As}_{2} \mathrm{~S}_{3}$, and $\mathrm{As}_{2} \mathrm{Se}_{3}$ fibers [78]. Figure 13a shows the corresponding setup for $\mathrm{SC}$ generation. The $\mathrm{As}_{2} \mathrm{~S}_{3}$ fiber was excited by the $\mathrm{SC}$ sources that was extended to $4.5 \mu \mathrm{m}$ from the ZBLAN fiber, generating an SC with a long wavelength edge of $7 \mu \mathrm{m}$, which is beyond the $\mathrm{ZDW}$ of the $\mathrm{As}_{2} \mathrm{Se}_{3}$ fiber $(6 \mu \mathrm{m})$. Finally, the cascading SC generation shown in Fig. 13b spanned a broadband spectrum from 1.6 to $>11 \mu \mathrm{m}$ from the $\mathrm{As}_{2} \mathrm{Se}_{3}$ step-index fibers, and produced a high output power of $417 \mathrm{~mW}$. Such an SC generation exhibited the properties of wide spectral coverage and high average power required for practical applications.

The SC output powers obtained from the above two cases are relatively high, while their price and complexity are still core issues for practical and widespread applications. In order to reduce the system complexity and maintain the SC output power close to hundred $\mathrm{mW}$ level at the same time, a configuration of the cascading SC source without thulium amplifier is employed and shown in Fig. 14a, where a section of passive $\mathrm{Tm}$ and Ge/Tm co-doped fibers were used between the silica fiber and ZBLAN fiber to redistribute the pump power above $2 \mu \mathrm{m}$ [79]. After the cascaded three stage fibers, the output spectrum of the SC source spans $1.46-10.46 \mu \mathrm{m}$ with an average output power of $86.6 \mathrm{~mW}$. This SC source is more compact, robust, and low-cost, and able to be packaged in a box with a size of $47.4 \times 30.0 \times 13.45 \mathrm{~cm}^{3}$, as shown in Fig. $14 \mathrm{~b}$.

In addition, there are still some details to be considered in cascading scheme that the length of each stage fiber should be optimized carefully to be short enough to prevent excess long wavelength loss and simultaneously long enough to maximize spectral expansion. Coupling between different kinds of fibers is also a great challenge for cascading scheme. The coupling efficiency can be improved to some extent by fiber 

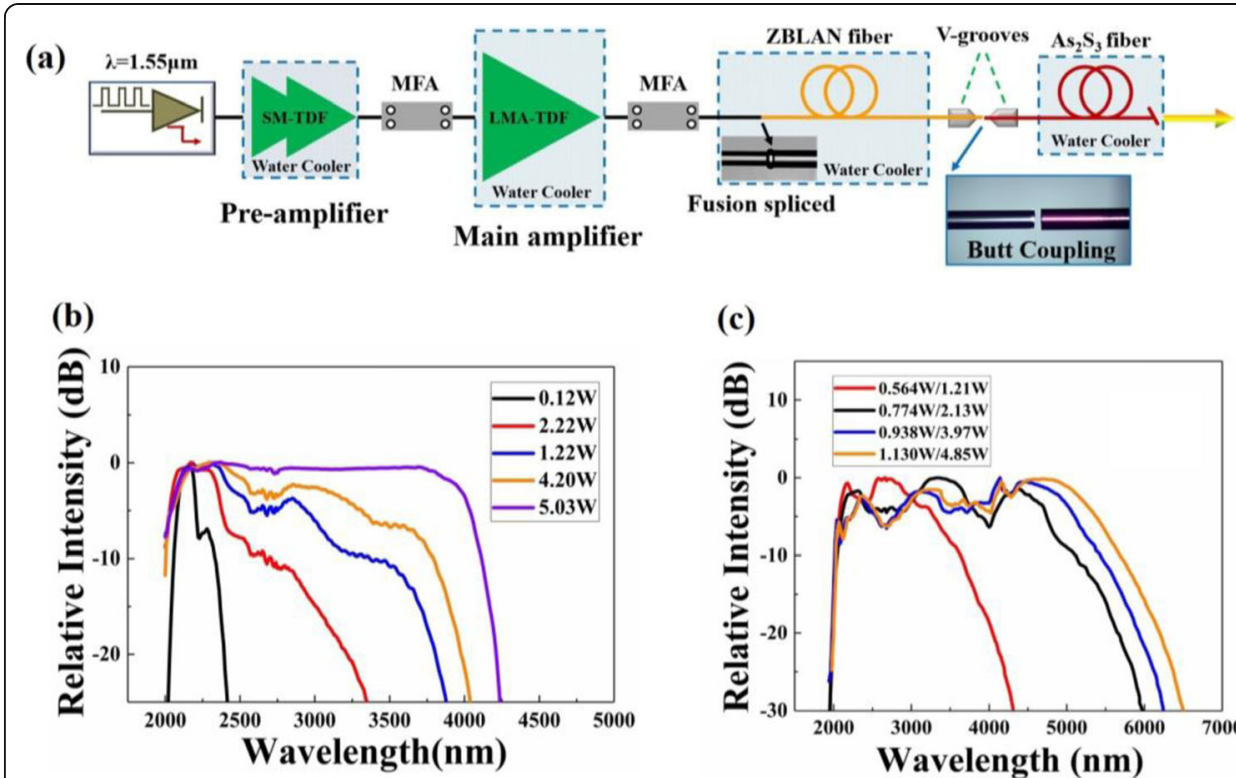

(b)

Fig. 12 a Setup of two-stage cascading scheme for all-fiber SC generation. b Measured SC spectra from ZBLAN with different output powers. c Measured SC spectra from $\mathrm{As}_{2} \mathrm{~S}_{3}$ fiber with different output power versus the input power (Adapted with permission from [29], copyright the Optical Society)

nanoimprinting [81] or coating the fiber endfacet with anti-reflection layer [82]. Especially, low loss splice fusion has been achieved between silica and fluoride, silica and ChG fibers to date $[71,83,84]$. The technical problem to be solved in the future is mainly the fusion splice between fluoride and ChG fibers. Similar with that pumping ChG fibers by fiber lasers, cascading scheme makes MIR SC sources more compact, low-cost, robust, and suitable for practical applications.

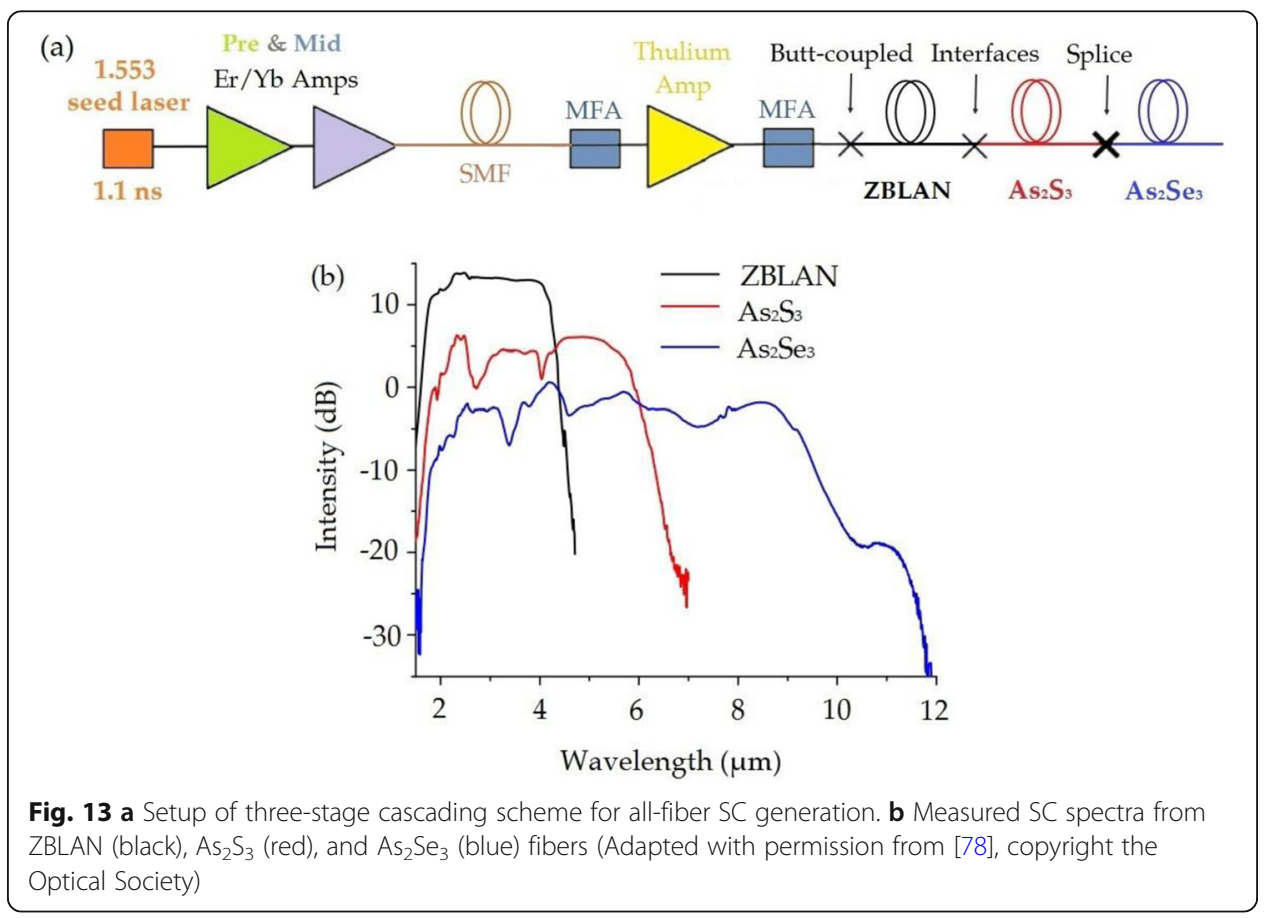




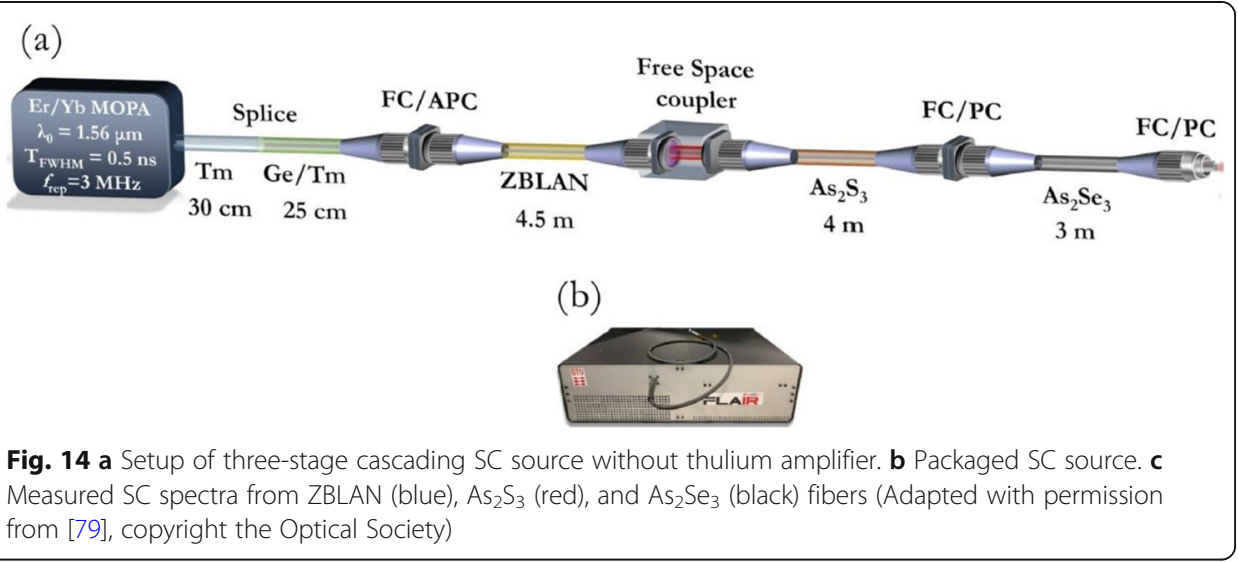

\section{Novel ChG fibers for MIR SC generation}

In addition to the commonly used $\mathrm{ChG}$ fibers such as $\mathrm{As}_{2} \mathrm{~S}_{3}, \mathrm{As}_{2} \mathrm{Se}_{3}$, and Ge-As-Se fibers, etc., novel ChG fibers have also been investigated and employed as nonlinear media for SC generation to further extend the spectral coverage and improve the output power.

\section{As-free fibers}

Most ChG fibers for SC generation, such as $\mathrm{As}_{2} \mathrm{~S}_{3}$ and $\mathrm{As}_{2} \mathrm{Se}_{3}$ fibers, contain the toxic element As. Thus, security issues may occur during glass preparation, fiber drawing, and performance testing [85]. Especially when the toxic materials are exposed to a laser power that is beyond the damage threshold of the materials, they could be burnt or evaporated. Obviously, these evaporated gases are extremely harmful to health.

Widely used $\mathrm{As}_{2} \mathrm{~S}_{3}$ and $\mathrm{As}_{2} \mathrm{Se}_{3}$ glasses have relatively low glass transition temperature (Tg) at $185^{\circ} \mathrm{C}$ and $178^{\circ} \mathrm{C}$, respectively. By contrast, Ge-Sb-Se glasses exhibit higher thermal and mechanical durability (http://www.amorphousmaterials.com/products/.) and have been demonstrated to be suitable for molded infrared-transmitting lenses. Meanwhile, the replacement of highly toxic As with $\mathrm{Sb}$ makes the $\mathrm{Ge}-\mathrm{Sb}-\mathrm{Se}$ glasses more environmentally favorable. Among Ge-Sb-Se glasses, the optical nonlinearity of the $\mathrm{Ge}_{15} \mathrm{Sb}_{25} \mathrm{Se}_{60}$ glass $\left(19 \times 10^{-18} \mathrm{~m}^{2} / \mathrm{W}\right)$ is greater than that of $\mathrm{As}_{2} \mathrm{Se}_{3}$ and Ge-As-Se glasses because of the replacement of As by more metallic Sb [21, 86, 87]. The most important thing is that visible damage arises at a beam intensity of $3674 \mathrm{GW} / \mathrm{cm}^{2}$ for $\mathrm{Ge}_{15} \mathrm{Sb}_{25} \mathrm{Se}_{60}$ glass at $3.0 \mu \mathrm{m}$, and the value is more than twice than that of $\mathrm{As}_{2} \mathrm{Se}_{3}$ glass, which is $1524 \mathrm{GW} / \mathrm{cm}^{2}$ [88]. The microscope images of laser-induced damage are shown in Fig. 15. This indicates that $\mathrm{Ge}_{15} \mathrm{Sb}_{25} \mathrm{Se}_{60}$ fibers can endure relatively higher peak power. Such a large nonlinearity and a high laser-induced damage threshold of the glass, makes the expectation to generate an ultra-broad MIR SC with high output power in $\mathrm{Ge}_{15} \mathrm{Sb}_{25} \mathrm{Se}_{60}$ fibers.

The Ge-Sb-Se fiber fabrication and SC generation have been demonstrated experimentally. In a 20-cm-long fiber with the core and cladding made of $\mathrm{Ge}_{15} \mathrm{Sb}_{25} \mathrm{Se}_{60}$ core and $\mathrm{Ge}_{15} \mathrm{Sb}_{20} \mathrm{Se}_{65}$ clad glasses, respectively, an $\mathrm{SC}$ generation spanning from 1.8 to $14 \mu \mathrm{m}$ was achieved pumped by $150 \mathrm{fs}$ pulses at $6.0 \mu \mathrm{m}$ in the anomalous dispersion regime [88]. Similarly, a $\mathrm{Ge}_{15} \mathrm{Sb}_{15} \mathrm{Se}_{70} / \mathrm{Ge}_{20} \mathrm{Sb}_{80}$ fiber with a core diameter of $6 \mu \mathrm{m}$ and 
fiber length of $11 \mathrm{~cm}$ was pumped at $4.485 \mu \mathrm{m}$ with $330 \mathrm{fs}$ pulses, and an SC covering the $2-12 \mu \mathrm{m}$ spectral range with an average output power of $\sim 17 \mathrm{~mW}$ was achieved, as shown in Fig. 16 [89]. These results indicate the significant potential of the $\mathrm{Ge}-\mathrm{Sb}-\mathrm{Se}$ fibers as nonlinear media for a broadband and bright MIR SC source.

\section{Te-based fibers}

While high optical nonlinearity is beneficial to SC generation, it is well known that the replacement of a lighter chalcogen element by a heavier one can enhance the optical nonlinearity of the glasses and extend the transparency window to much longer wavelengths. Te-based glasses have low phonon energies and high linear refractive indices, which result in wide optical windows and high nonlinear refractive indices [42, 90-92]. Thus, a relatively wider SC generation extending to FIR can be expected from Te-based fibers.

However, the introduction of Te always shifts the ZDW of ChG fibers to wavelengths longer than $9 \mu \mathrm{m}$. Although the waveguide dispersion can be engineered by fiber structure design such as MOF and TF, the blue shift of ZDW is relatively limited. As can be seen in Fig. 17a and b, when the fiber core diameter is less than $20 \mu \mathrm{m}$, it even tends to exhibit no ZDW property [93, 94]. Figure $17 \mathrm{c}$ is an SC source spanning from 2 to $14 \mu \mathrm{m}$ generated from a $\mathrm{Ge}_{20} \mathrm{As}_{20} \mathrm{Se}_{15} \mathrm{Te}_{45}$ fiber with all-normal dispersion, showing a high coherence in all wavelengths and a flatness in 2.9-13.1 $\mu \mathrm{m}$ within $-10 \mathrm{~dB}$ dynamic range.

However, the metallic characteristic of Te can lead to a greater tendency for crystallite formation, which may prevent the production of low-loss optical fibers due to the scattering effects. A second consequence of the metallic characteristic of Te is a low bandgap that results in significant background carrier absorption caused by thermally excited charge carriers at room temperature, leading to high transmission loss for Tebased fibers (see in Fig. 17d). Though these drawbacks can be alleviated by substituting a small amount of $\mathrm{Te}$ by Se to lower the conductivity and dramatically increases the resistance to crystallization while retaining a wide optical window in the long wavelengths, the optical fiber loss still needs to be decreased to fit the requirements of SC generation and other applications.
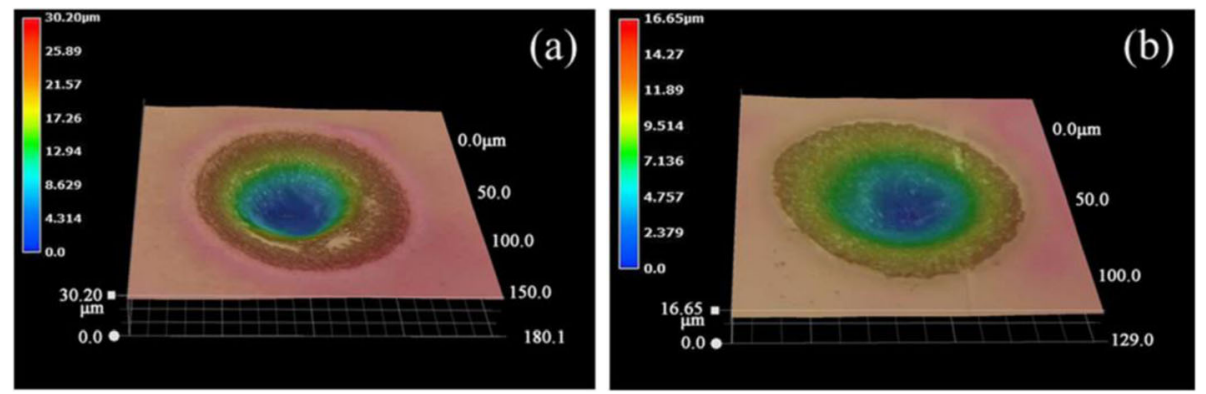

Fig. 15 Optical microscope images of laser-induced damage sites after irradiation with a $3 \mu \mathrm{m} f \mathrm{fs}$ laser at 30 $\mathrm{mW}$ and $20 \mathrm{~s}$ duration. a $\mathrm{As}_{2} \mathrm{Se}_{3}$ glass; $\mathbf{b} \mathrm{Ge}_{15} \mathrm{Sb}_{25} \mathrm{Se}_{60}$ glass (Adapted with permission from [88], copyright the Optical Society) 


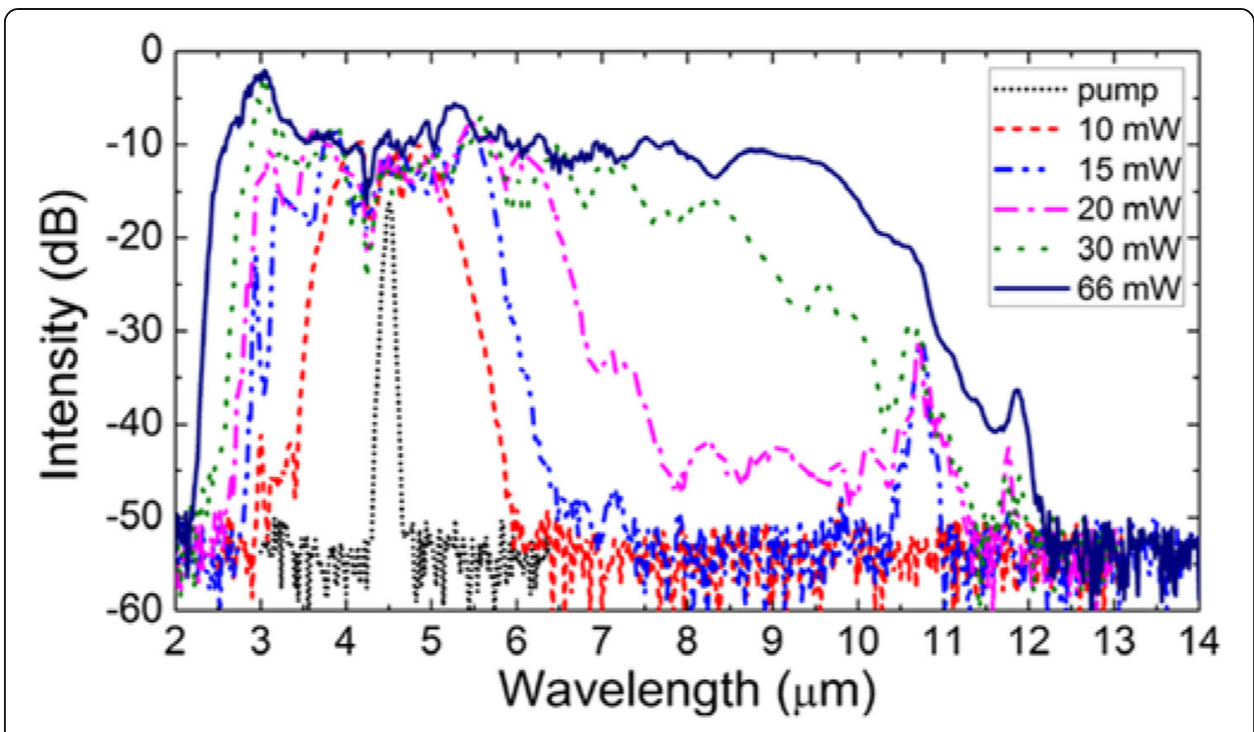

Fig. 16 Broadband MIR SC generation in a $\mathrm{Ge}_{15} \mathrm{Sb}_{15} \mathrm{Se}_{70} / \mathrm{Ge}_{20} \mathrm{Sb}_{80}$ fiber pumped at $4.485 \mu \mathrm{m}$ with $330 \mathrm{fs}$ pulses (Adapted with permission from [89], copyright John Wiley \& Sons)
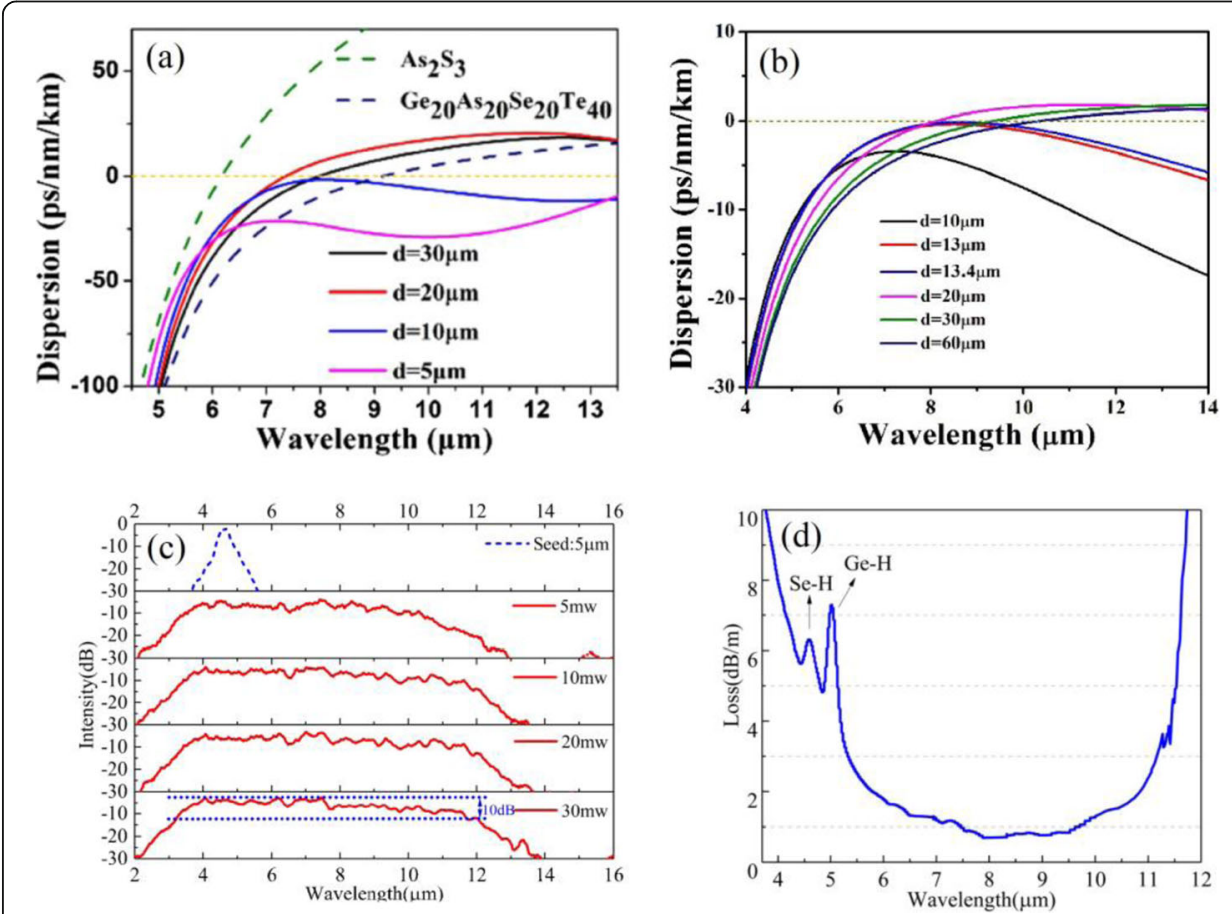

Fig. 17 a Calculated material dispersion of $\mathrm{As}_{2} \mathrm{~S}_{3}$ and $\mathrm{Ge}_{20} \mathrm{As}_{20} \mathrm{Se}_{20} \mathrm{Te}_{40}$ glasses and fiber dispersion curves with various core diameters (Adapted with permission from [93], copyright the Optical Society). b Calculated fundamental mode dispersion characteristic curves of Te-based ChG fibers with various core diameters (Adapted with permission from [94], copyright the Optical Society). c SC generation from a $\mathrm{Ge}_{20} \mathrm{As}_{20} \mathrm{Se}_{15} \mathrm{Te}_{45}$ fiber with all-normal dispersion pumped by different input powers at $5 \mu \mathrm{m}$. $\mathbf{d}$ Optical loss of the $\mathrm{Ge}_{20} \mathrm{As}_{20} \mathrm{Se}_{15} \mathrm{Te}_{45}$ fiber (Adapted with permission from [95], copyright the Optical Society) 


\section{ChH fibers}

$\mathrm{ChH}$ glasses combining chalcogen with halogen or metal halide offer a path for tuning optical properties, such as optical band-gap, transmission window, refractive index, etc. Taking $\mathrm{GeSe}_{2}-\mathrm{Ga}_{2} \mathrm{Se}_{3}-\mathrm{CsI}$ as an example [96], the optical band-gap increases gradually with the content of CsI, as shown in Fig. 18a, resulting in the increase of absorption edge and excellent transmission at shorter wavelength. Simultaneously, the $\mathrm{GeSe}_{2}$ $\mathrm{Ga}_{2} \mathrm{Se}_{3}-\mathrm{CsI}$ glasses exhibit better transparency in IR than the traditional ChG glasses. Moreover, the higher the content of CsI in ChH glass, the shorter the ZDW of the fiber. As can be seen in Fig. $18 \mathrm{~b}, 55 \mathrm{GeSe}_{2}-25 \mathrm{Ga}_{2} \mathrm{Se}_{3}-20 \mathrm{CsI}$ fiber shows a ZDW of $3.5 \mu \mathrm{m}$, and $36 \mathrm{GeSe}_{2}-24 \mathrm{Ga}_{2} \mathrm{Se}_{3}-40 \mathrm{CsI}$ fiber even has a shorter ZDW of $2.2 \mu \mathrm{m}$.

When pumping a $\mathrm{GeSe}_{2}-\mathrm{Ga}_{2} \mathrm{Se}_{3}-\mathrm{CsI}$ fiber with $150 \mathrm{fs}$ pulses at a repetition rate of 1 $\mathrm{kHz}$ and a wavelength of $6.3 \mu \mathrm{m}$, which is located at the water absorption peak, a broadband SC spanning from 1.05 to $13.0 \mu \mathrm{m}$ was generated (Fig. 18d). Such a spectral broadening is dominated by soliton dynamics in the anomalous dispersion regime. Due to the increasing band-gap by metal halide doping, a blueshift of SC spectrum down to $1 \mu \mathrm{m}$ is obtained, which is unreachable in As-S fibers. However, because of the volatility and deliquescence of halide, the raw material cannot be purified via chemical deposition and vacuum distillation. In addition, high temperature during the fiber fabrication would boost the volatilization of halide and contaminate the glass preform. Therefore, further spectral broadening was hindered by the high fiber loss with a minimum loss of $4.15 \mathrm{~dB} / \mathrm{m}$ at $7 \mu \mathrm{m}$ (Fig. 18c).

As can be seen in Fig. 19, by peeling off the defective surface layer of $\mathrm{ChH}$ glasses to reduce the volatilization of halide [98], a low-loss $\mathrm{Ge}_{10} \mathrm{As}_{22} \mathrm{Se}_{68}-\mathrm{I} \mathrm{ChH}$ fiber with a minimum fiber loss of $1.12 \mathrm{~dB} @ 6.4 \mu \mathrm{m}$ was fabricated [97]. Meanwhile, the fiber zero fundamental mode dispersion is adjusted to $4.03 \mu \mathrm{m}$ from the MZDW of $7 \mu \mathrm{m}$. Pumped with $150 \mathrm{fs}$ pulses at a repetition rate of $1 \mathrm{kHz}$ under different wavelengths,
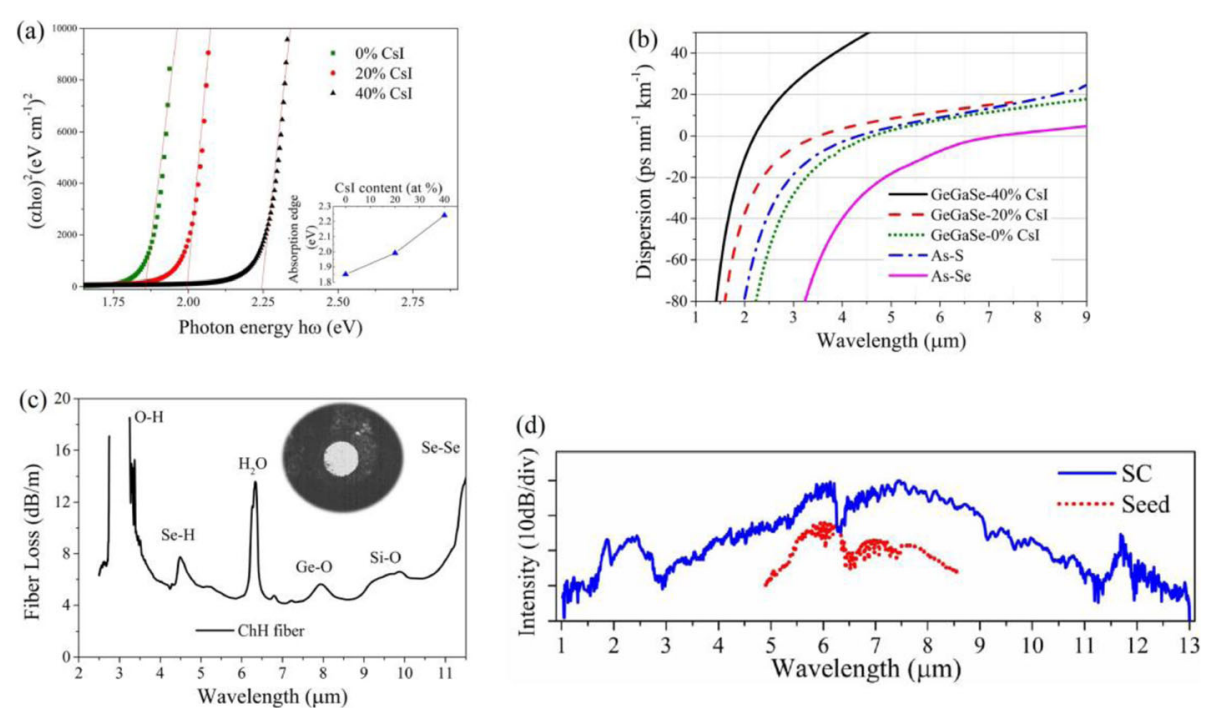

Fig. 18 a optical absorption edge of the Ge-Ga-Se-Csl glasses (the inset shows the absorption edge values) b Calculated material dispersion of $\mathrm{ChH}$ glasses. c optical loss of the $\mathrm{ChH}$ fiber. $\mathbf{d} \mathrm{SC}$ generation in the $\mathrm{ChH}$ fiber pumped at $6.3 \mu \mathrm{m}$ (Adapted with permission from [96], copyright John Wiley \& Sons) 
broadband SC spectra were generated. It is shown that the SC spectrum pumped at $8 \mu \mathrm{m}$ exhibits a wideset spectral coverage of $1.2-15.2 \mu \mathrm{m}$.

\section{Applications}

Broadband and high-brightness MIR SC sources based on ChG fibers not only break the limitation of few MIR lasers available but also offer lower cost, more compact system, and wider spectral bandwidth than OPA, OPO, and quantum cascade lasers. Meanwhile, MIR wavelength range covers the molecular fingerprint region [99] and spans three atmospheric transmission windows [36]. Therefore, it is believed that MIR SC sources have the ability to expand applications which have not been explored or well developed because of the lack of suitable light sources.

MIR spectroscopy is a new technique for diagnosing healthy and diseased tissues in the field of biomedical imaging in recent years. Because many biochemical tissues have distinguished absorption spectra in MIR, the absorption characteristics of these fingerprint spectra can be used to identify the types of trace chemicals, so as to provide data support for the discrimination of various diseases. The demonstration of multispectral imaging with MIR SC sources at wavelength beyond $5 \mu \mathrm{m}$ was firstly reported based on a ChG tapered PCF, in which an SC spanning 2-7.5 $\mu \mathrm{m}$ with an output power of 25 $\mathrm{mW}$ generated by pumping at $4.3 \mu \mathrm{m}$ [10]. Then the SC source was long-pass filtered
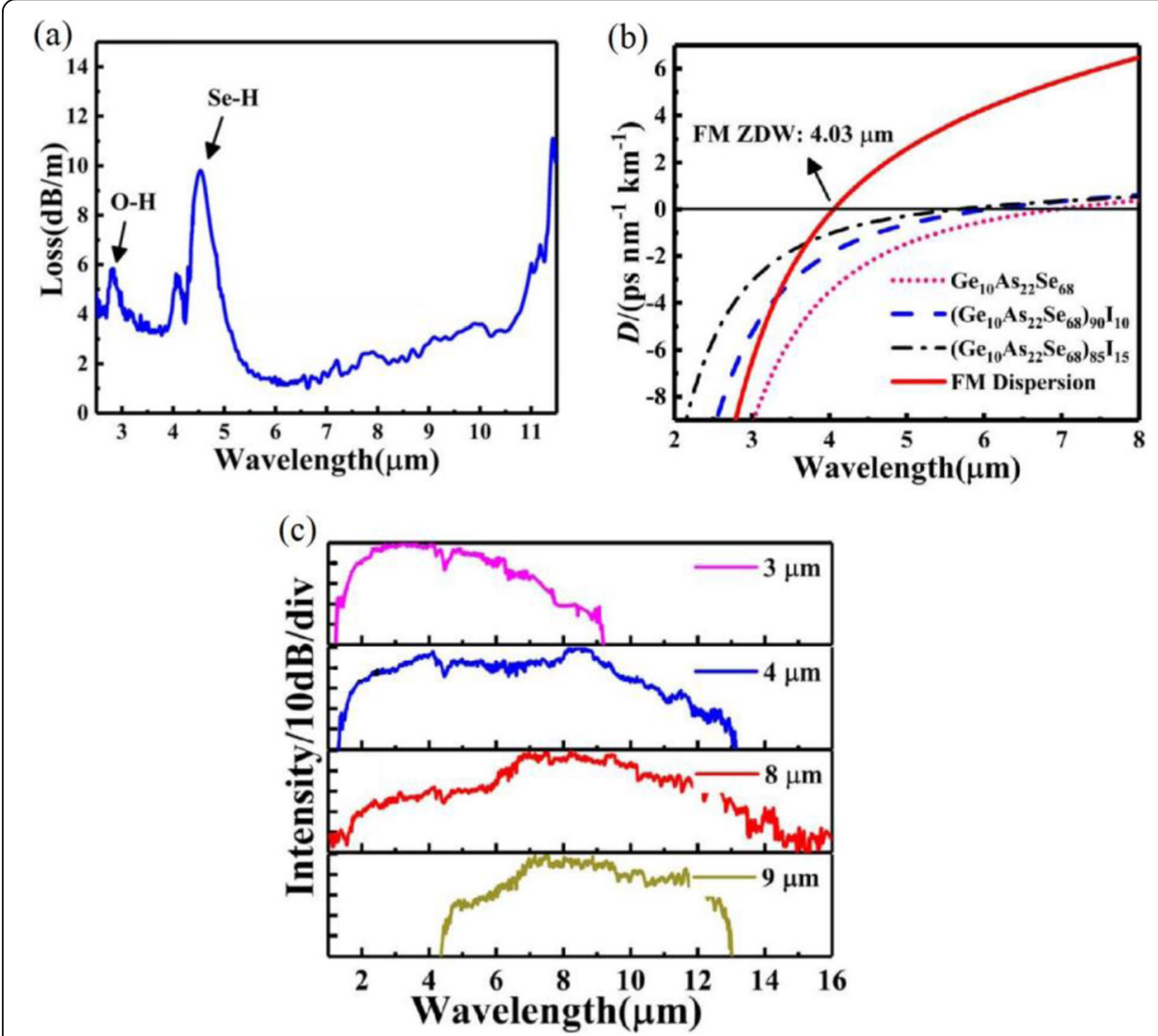

Fig. 19 a Fiber loss of the $\mathrm{Ge}_{10} \mathrm{As}_{22} \mathrm{Se}_{68}-\mathrm{ChH}$ fiber. $\mathbf{b}$ calculated the material dispersion and the fundamental mode dispersion curves of the $\mathrm{Ge}_{10} \mathrm{As}_{22} \mathrm{Se}_{68^{-1}} \mathrm{ChH}$ fiber. c SC spectra from the $\mathrm{Ge}_{10} \mathrm{As}_{22} \mathrm{Se}_{68}-1$ $\mathrm{ChH}$ fiber pumped with different wavelengths (Adapted with permission from [97], copyright the Optical Society) 
at $4.5 \mu \mathrm{m}$, allowing the power to be focused onto the sample of 9-10 $\mathrm{mW}$. Here the sample was a section of nontumoral colon tissue with $7 \mu \mathrm{m}$ thickness, which was pointscanned at different wavelengths where the cancer tissue exhibited some key molecular absorptions. A grating spectrometer for wavelength selection was used before a lock-in MCT detector. As can be seen in Fig. 20, the amide rich nuclear regions of the colonic crypts can be distinguished from the surrounding connective tissue. Compared with the commonly used FTIR imaging technology, this method can reduce the noise intensity of each image along the scanning length as long as the SC power spectral intensity is sufficient. Therefore, the MIR SC sources can be effectively used for multispectral tissue imaging, making it promising for early diagnosis of many diseases, which is often the key to successful treatment.

Besides, most molecules exhibit distinctive spectral fingerprints in MIR spectral region for their different vibration absorptions originating from the chemical bonds or functional groups [13]. Hence, MIR absorption spectra can be used to identify and quantify material molecules, especially the detection and concentration of multicomponents gas mixtures in industrial process and pollution monitoring [5, 100], and stand-off detection of solid targets such as explosives and paint coatings [9, 101, 102]. Compared with MIR lasers with single operation wavelength or difficult tuning process, MIR SC sources with broadband spectrum and high coherence show great advantages in molecular detection.

In addition, the directed infrared countermeasures (DIRCM) system is also a significant potential application of MIR SC sources [9]. Various heat seeking weapons have become an important threaten to civil and military aircraft. DIRCM system with an IR laser which can lase in several bands, mainly the 2 and $4.3 \mu \mathrm{m}$ atmospheric
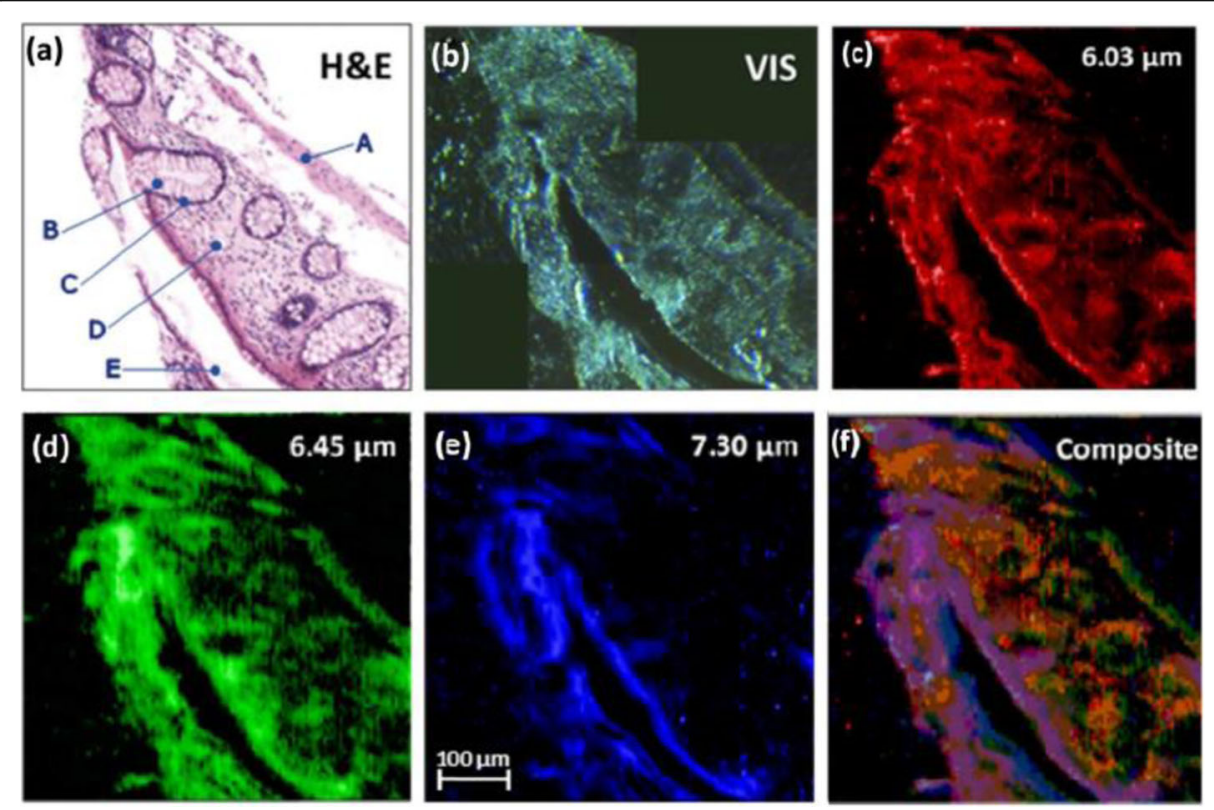

Fig. 20 Comparison between a the confocal image of the H\&E stained tissue section with identification of the various histological regions, $\mathbf{b}$ transmission image of the unstained sample at visible light, $\mathbf{c}, \mathbf{d}$ MIR absorbance images of the protein rich amide regions highlighting the nuclear regions of the colonic crypts, e the mucin secretions and surface epithelial walls, and $\mathbf{f}$ Composite image showing the spectral-spatial mapping of c-e (Adapted with permission from [10], copyright the Optical Society) 
transmission windows, is an effective means against heat seeking weapons. As the DIRCM develops from IR laser jamming to dazzling and breakdown, the required average power of the laser source is constantly increasing, and the spectral bandwidth needs to be a continuous spectrum which cover all wavelengths from below $2 \mu \mathrm{m}$ and up to $14 \mu \mathrm{m}$. Thus, MIR SC sources with sufficient average power and good long-term operation will be a candidate for future DIRCM systems.

However, rarely reports on these applications of MIR SC sources from ChG fibers can be found to date due to their poor noise performance and system instability. With the improvement of their spectral bandwidth, average power, coherent property, repetition rate, and especially the all-fiber structure, we believe that MIR SC sources with good performance from ChG fibers are likely to become commercially available and appear in many potential applications in the near future.

\section{Conclusions}

In summary, we have reviewed the development progress of MIR SC generation in ChG fibers. Considerable progress has been made in MIR SC generation from ChG fibers over the past decade due to their advantages of a wider transparency window and higher optical nonlinearity. In terms of spectral bandwidth, an SC spanning of $14 \mu \mathrm{m}$ from 2 to $16 \mu \mathrm{m}$ has been achieved, which covers the entire molecular fingerprint region and IR transmission windows of atmosphere. In terms of output power, an average power of watt magnitude has also been realized in a cascading SC source scheme, although it still needs to be improved for many practical applications. In addition, the implementation of a packaged all-fiber construction makes MIR SC sources more robust, portable, and ideal for long-term stability and reliability. To satisfy various applications such as spectroscopy, gas and solid detection, and DIRCM, etc., properties of MIR SC Sources including coherence, pulse duration, and repetition rate are also required to be optimized besides the spectral bandwidth and average output power.

Acknowledgements

Not applicable.

Authors' contributions

YW prepared the manuscript. SD revised the manuscript. The authors read and approved the final manuscript.

Funding

National Natural Science Foundations of China (NSFCS) (Nos. 61875094, 62090064), and K.C. Wong Magna Fund in

Ningbo University.

Availability of data and materials

Data sharing is not applicable to this article as no new data were created or analyzed in this study.

\section{Declarations}

Competing interests

The authors declare that they have no competing interests.

Author details

${ }^{1}$ Laboratory of Infrared Material and Devices, The Research Institute of Advanced Technologies, Ningbo University, Ningbo 315211, China. ${ }^{2}$ Key Laboratory of Photoelectric Materials and Devices of Zhejiang Province, Ningbo 315211 , China. ${ }^{3}$ Engineering Research Center for Advanced Infrared Photoelectric Materials and Devices of Zhejiang Province, Ningbo 315211, China. 
Received: 23 March 2021 Accepted: 9 May 2021

Published online: 04 June 2021

\section{References}

1. Agrawal GP. Nonlinear fiber optics. Fifth edition. Amsterdam: Elsevier; 2013.

2. Price JHV, Feng $X$, Heidt AM, Brambilla G, Horak P, Poletti F, et al. Supercontinuum generation in non-silica fibers. Opt Fiber Technol. 2012;18(5):327-44. https://doi.org/10.1016/j.yofte.2012.07.013.

3. Dudley JM, Genty G, Coen S. Supercontinuum generation in photonic crystal fiber. Rev Mod Phys. 2006;78(4):1135-84. https://doi.org/10.1103/RevModPhys.78.1135.

4. Alfano RR, Shapiro SL. Observation of self-phase modulation and small-scale filaments in crystals and glasses. Phys Rev Lett. 1970;24(11):592-4. https://doi.org/10.1103/PhysRevLett.24.592.

5. Nicolas C, Alexandre D, Guillaume C, Mathieu D, William R, Claire AG, et al. Supercontinuum laser absorption spectroscopy in the mid-infrared range for identification and concentration estimation of a multi-component atmospheric gas mixture. Proc.SPIE. 2011;8182. https://doi.org/10.1117/12.898227.

6. Amiot C, Aalto A, Ryczkowski P, Toivonen J, Genty G. Cavity enhanced absorption spectroscopy in the mid-infrared using a supercontinuum source. Appl Phys Lett. 2017;111(6):061103. https://doi.org/10.1063/1.4985263.

7. Jahromi EK, Nematollahi M, Pan Q, Abbas MA, Cristescu SM, Harren FJM, et al. Sensitive multi-species trace gas sensor based on a high repetition rate mid-infrared supercontinuum source. Opt Express. 2020;28(18):26091-101. https://doi. org/10.1364/OE.396884

8. Seddon AB. A prospective for new mid-infrared medical endoscopy using chalcogenide glasses. Int J Appl Glas Sci. 2011;2(3):177-91. https://doi.org/10.1111/j.2041-1294.2011.00059.x.

9. Moselund P, Petersen C, Dupont S, Agger C, Bang O, Keiding SR. Supercontinuum: broad as a lamp, bright as a laser now in the mid-infrared. Proc.SPIE. 2012;83811A. https://doi.org/10.1117/12.920094.

10. Petersen CR, Prtljaga N, Farries M, Ward J, Napier B, Lloyd GR, et al. Mid-infrared multispectral tissue imaging using a chalcogenide fiber supercontinuum source. Opt Lett. 2018;43(5):999-1002. https://doi.org/10.1364/OL.43.000999.

11. Cheung CS, Daniel JMO, Tokurakawa M, Clarkson WA, Liang H. High resolution Fourier domain optical coherence tomography in the $2 \mu \mathrm{m}$ wavelength range using a broadband supercontinuum source. Opt Express. 2015;23(3):19922001. https://doi.org/10.1364/OE.23.001992.

12. Israelsen NM, Petersen $C R$, Barh $A$, Jain $D$, Jensen $M$, Hannesschläger $G$, et al. Real-time high-resolution mid-infrared optical coherence tomography. Light Sci Appl. 2019;8(11). https://doi.org/10.1038/s41377-019-0122-5.

13. Schliesser A, Picqué N, Hänsch TW. Mid-infrared frequency combs. Nat Photonics. 2012;6(7):440-9. https://doi.org/10.103 8/nphoton.2012.142.

14. Xia C, Kumar M, Kulkarni OP, Islam MN, Terry JFL, Freeman MJ, et al. Mid-infrared supercontinuum generation to $4.5 \mu \mathrm{m}$ in ZBLAN fluoride fibers by nanosecond diode pumping. Opt Lett. 2006;31(17):2553-5. https://doi.org/10.1364/OL.31.002 553.

15. Yang W, Zhang B, Xue G, Yin K, Hou J. Thirteen watt all-fiber mid-infrared supercontinuum generation in a single mode ZBLAN fiber pumped by a 2 4m MOPA system. Opt Lett. 2014;39(7):1849-52. https://doi.org/10.1364/OL.39.001849.

16. Qin G, Yan X, Kito C, Liao M, Chaudhari C, Suzuki T, et al. Ultrabroadband supercontinuum generation from ultraviolet to $6.28 \mu \mathrm{m}$ in a fluoride fiber. Appl Phys Lett. 2009;95(16):161103.

17. Swiderski J, Michalska M, Maze G. Mid-IR supercontinuum generation in a ZBLAN fiber pumped by a gain-switched mode-locked tm-doped fiber laser and amplifier system. Opt Express. 2013;21(7):7851-7. https://doi.org/10.1364/OE.21. 007851.

18. Yang L, Li Y, Zhang B, Wu T, Zhao Y, Hou J. 30-W supercontinuum generation based on ZBLAN fiber in an all-fiber configuration. Photon Res. 2019;7(9):1061-5. https://doi.org/10.1364/PRJ.7.001061.

19. Domachuk P, Wolchover NA, Cronin-Golomb M, Wang A, George AK, Cordeiro CMB, et al. Over 4000 nm bandwidth of mid-IR supercontinuum generation in sub-centimeter segments of highly nonlinear tellurite PCFs. Opt Express. 2008; 16(10):7161-8. https://doi.org/10.1364/OE.16.007161.

20. Liao M, Gao W, Duan Z, Yan X, Suzuki T, Ohishi Y. Supercontinuum generation in short tellurite microstructured fibers pumped by a quasi-cw laser. Opt Lett. 2012;37(11):2127-9. https://doi.org/10.1364/OL.37.002127.

21. Yu Y, Zhang B, Gai X, Zhai C, Qi S, Guo W, et al. 1.8-10 $\mu \mathrm{m}$ mid-infrared supercontinuum generated in a step-index chalcogenide fiber using low peak pump power. Opt Lett. 2015;40(6):1081-4. https://doi.org/10.1364/OL.40.001081.

22. Saini TS, Kumar A, Kumar SR. Broadband mid-IR supercontinuum generation in $\mathrm{As}_{2} \mathrm{Se}_{3}$ based chalcogenide photonic crystal fiber: A new design and analysis. Opt Commun. 2015;347:13-9. https://doi.org/10.1016/j.optcom.2015.02.049.

23. Al-Kadry A, Li L, Amraoui ME, North T, Messaddeq Y, Rochette M. Broadband supercontinuum generation in all-normal dispersion chalcogenide microwires. Opt Lett. 2015;40(20):4687-90. https://doi.org/10.1364/OL.40.004687.

24. Sun $Y$, Dai S, Zhang P, Wang $X, X u Y$, Liu Z, et al. Fabrication and characterization of multimaterial chalcogenide glass fiber tapers with high numerical apertures. Opt Express. 2015;23(18):23472-83. https://doi.org/10.1364/OE.23.023472.

25. Zhao Z, Wu B, Wang X, Pan Z, Liu Z, Zhang P, et al. Mid-infrared supercontinuum covering 2.0-16 $\mu \mathrm{m}$ in a low-loss telluride single-mode fiber. Laser Photonics Rev. 2017;11(2):1700005.

26. Shiryaev VS, Churbanov MF. Trends and prospects for development of chalcogenide fibers for mid-infrared transmission. J Non-Cryst Solids. 2013;377:225-30.

27. Cui S, Chahal R, Boussard-Plédel C, Nazabal V, Doualan JL, Troles J, et al. From Selenium- to Tellurium-Based Glass Optical Fibers for Infrared Spectroscopies. Molecules. 2013;18(5):5373-88. https://doi.org/10.3390/molecules 18055373.

28. Slusher RE, Lenz G, Hodelin J, Sanghera J, Shaw LB, Aggarwal ID. Large Raman gain and nonlinear phase shifts in highpurity $\mathrm{As}_{2} \mathrm{Se}_{3}$ chalcogenide fibers. J. Opt. Soc. Am. B. 2004;21(6):1146-55. https://doi.org/10.1364/JOSAB.21.001146.

29. Yan B, Huang T, Zhang W, Wang J, Yang L, Yang P, et al. Generation of watt-level supercontinuum covering 2-6.5 $\mu \mathrm{m}$ in an all-fiber structured infrared nonlinear transmission system. Opt Express. 2021;29(3):4048-57. https://doi.org/10.1364/ OE.415534.

30. Borisova ZU. Glassy Semiconductors: Springer; 1981

31. Wang R, Zha CJ, Rode AV, Madden SJ, Luther-Davies B. Thermal characterization of Ge-as-se glasses by differential scanning calorimetry. J Mater Sci-Mater El. 2007;18(1):419-22. https://doi.org/10.1007/s10854-007-9229-1. 
32. Yang Z, Gulbiten O, Lucas P, Luo T, Jiang S. Long-wave infrared-transmitting optical fibers. J Am Ceram Soc. 2011;94(6): 1761-5. https://doi.org/10.1111/j.1551-2916.2010.04313.x.

33. Sivakumaran K, Nair CKS. Rapid synthesis of chalcogenide glasses of se-Te-Sb system by microwave irradiation. J Phys D Appl Phys. 2005;38(14):2476-9. https://doi.org/10.1088/0022-3727/38/14/026.

34. Thompson D, Danto S, Musgraves JD, Wachtel P, Giroire B, Richardson K. Microwave assisted synthesis of high purity $\mathrm{As}_{2} \mathrm{Se}_{3}$ chalcogenide glasses. Physics Chem Glasses Eur J Glass Sci Technol Part B. 2013;54(1):27-34.

35. Katsuyama T, Satoh S, Matsumura H. Fabrication of high-purity chalcogenide glasses by chemical vapor deposition. J Appl Phys. 1986;59(5):1446-9. https://doi.org/10.1063/1.336496.

36. Tao G, Ebendorff-Heidepriem H, Stolyarov AM, Danto S, Badding JV, Fink Y, et al. Infrared fibers. Adv Opt Photon. 2015; 7(2):379-458. https://doi.org/10.1364/AOP.7.000379.

37. Pelusi MD, Ta'eed VG, Fu L, Magi E, Lamont MRE, Madden S, et al. Applications of highly-nonlinear chalcogenide glass devices tailored for high-speed all-optical signal processing. IEEE J Sel Top Quant. 2008;14(3):529-39.

38. Sanghera JS, Aggarwal ID. Active and passive chalcogenide glass optical fibers for IR applications: a review. J Non-Cryst Solids. 1999;256-257:6-16.

39. Sanghera JS, Florea CM, Shaw LB, Pureza P, Nguyen VQ, Bashkansky M, et al. Non-linear properties of chalcogenide glasses and fibers. J Non-Cryst Solids. 2008;354(2-9):462-7. https://doi.org/10.1016/j.jnoncrysol.2007.06.104.

40. Nishii J, Yamashita T, Yamagishi T. Low-loss chalcogenide glass fiber with core-cladding structure. Appl Phys Lett. 1988; 53(7):553-4. https://doi.org/10.1063/1.99854.

41. Zhang B, Guo W, Yu Y, Zhai C, Qi S, Yang A, et al. Low loss, high NA chalcogenide glass fibers for broadband midinfrared supercontinuum generation. J Am Ceram Soc. 2015;98(5):1389-92. https://doi.org/10.1111/jace.13574.

42. Jayasuriya D, Petersen CR, Furniss D, Markos C, Tang Z, Habib MS, et al. Mid-IR supercontinuum generation in birefringent, low loss, ultra-high numerical aperture Ge-as-se-Te chalcogenide step-index fiber. Opt Mater Express. 2019; 9(6):2617-29.

43. Furniss D, Seddon AB. Towards monomode proportioned fibreoptic preforms by extrusion. J Non-Cryst Solids. 1999; 256(99):232-6.

44. Jiang $\mathrm{C}$, Wang $\mathrm{X}$, Zhu M, Xu H, Nie Q, Dai S, et al. Preparation of chalcogenide glass fiber using an improved extrusion method. Opt Eng. 2016;55(5):056114. https://doi.org/10.1117/1.OE.55.5.056114.

45. Baker C, Rochette M. Highly nonlinear hybrid AsSe-PMMA microtapers. Opt Express. 2010;18(12):12391-8. https://doi. org/10.1364/OE.18.012391.

46. Russell P. Photonic crystal fibers. Science. 2003;299(5605):358-62. https://doi.org/10.1126/science.1079280.

47. Renversez G, Kuhlmey B, McPhedran R. Dispersion management with microstructured optical fibers: ultraflattened chromatic dispersion with low losses. Opt Lett. 2003;28(12):989-91. https://doi.org/10.1364/OL.28.000989.

48. Schuster K, Kobelke J, Grimm S, Schwuchow A, Kirchhof J, Bartelt H, et al. Microstructured fibers with highly nonlinear materials. Opt Quant Electron. 2007;39(12):1057-69. https://doi.org/10.1007/s11082-007-9161-X.

49. Wang P, Huang J, Xie S, Troles J, Russell PS. Broadband mid-infrared supercontinuum generation in dispersionengineered $\mathrm{As}_{2} \mathrm{~S}_{3}$-silica nanospike waveguides pumped by $2.8 \mu \mathrm{m}$ femtosecond laser. Photon Res. 2021;9(4):630-6. https://doi.org/10.1364/PRJ.415339.

50. Wang Y, Dai S, Li G, Xu D, You C, Han X, et al. 1.4-7.2 $\mu \mathrm{m}$ broadband supercontinuum generation in an As-S chalcogenide tapered fiber pumped in the normal dispersion regime. Opt Lett. 2017:42(17):3458-61. https://doi.org/1 $0.1364 /$ OL.42.003458.

51. Désévédavy F, Renversez G, Brilland L, Houizot P, Troles J, Coulombier Q, et al. Small-core chalcogenide microstructured fibers for the infrared. Appl Opt. 2008;47(32):6014-21. https://doi.org/10.1364/AO.47.006014.

52. Brilland L, Smektala F, Renversez G, Chartier T, Troles J, Nguyen TN, et al. Fabrication of complex structures of holey fibers in Chalcogenide glass. Opt Express. 2006;14(3):1280-5. https://doi.org/10.1364/OE.14.001280.

53. Coulombier Q, Brilland L, Houizot P, Chartier T, Nguyen TN, Smektala F, et al. Casting method for producing low-loss chalcogenide microstructured optical fibers. Opt Express. 2010;18(9):9107-12. https://doi.org/10.1364/OE.18.009107.

54. Ghosh AN, Meneghetti M, Petersen CR, Bang O, Brilland L, Venck S, et al. Chalcogenide-glass polarization-maintaining photonic crystal fiber for mid-infrared supercontinuum generation. J Phys Photonics. 2019;1 (4):044003. https://doi.org/1 0.1088/2515-7647/ab3b1e.

55. Troles J, Coulombier Q, Canat G, Duhant M, Renard W, Toupin P, et al. Low loss microstructured chalcogenide fibers for large non linear effects at $1995 \mathrm{~nm}$. Opt Express. 2010;18(25):26647-54. https://doi.org/10.1364/OE.18.026647.

56. Mouawad O, Picot-Clémente J, Amrani F, Strutynski C, Fatome J, Kibler B, et al. Multioctave midinfrared supercontinuum generation in suspended-core chalcogenide fibers. Opt Lett. 2014;39(9):2684-7. https://doi.org/10.1364/OL.39.002684.

57. Mouawad O, Kedenburg S, Steinle T, Steinmann A, Kibler B, Désévédavy F, et al. Experimental long-term survey of midinfrared supercontinuum source based on $\mathrm{As}_{2} \mathrm{~S}_{3}$ suspended-core fibers. Appl Phys B Lasers Opt. 2016;122(6):177. https:// doi.org/10.1007/s00340-016-6453-5.

58. Shaw LB, Thielen PA, Kung FH, Nguyen VQ, Sanghera JS, Aggarwal ID. IR Supercontinuum eneration in As-Se Photonic crystal fiber. inAdvanced Solid-State Photonics, Technical Digest (Optical Society of America, 2005): TuC5. https://doi. org/10.1364/ASSP.2005.TuC5.

59. Wei DP, Galstian TV, Smolnikov IV, Plotnichenko VG, Zohrabyan A. Spectral broadening of femtosecond pulses in a single-mode as-S glass fiber. Opt Express. 2005;13(7):2439-43. https://doi.org/10.1364/OPEX.13.002439.

60. Gattass RR, Shaw LB, Nguyen VQ, Pureza PC, Aggarwal ID, Sanghera JS. All-fiber chalcogenide-based mid-infrared supercontinuum source. Opt Fiber Technol. 2012;18(5):345-8. https://doi.org/10.1016/.jyofte.2012.07.003.

61. Petersen CR, Møller U, Kubat I, Zhou B, Dupont S, Ramsay J, et al. Mid-infrared supercontinuum covering the 1.4-13.3 $\mu \mathrm{m}$ molecular fingerprint region using ultra-high NA chalcogenide step-index fibre. Nat Photonics. 2014;8(11):830-4. https://doi.org/10.1038/nphoton.2014.213.

62. Hudson DD, Dekker SA, Mägi EC, Judge AC, Jackson SD, Li E, et al. Octave spanning supercontinuum in an $\mathrm{As}_{2} \mathrm{~S}_{3}$ taper using ultralow pump pulse energy. Opt Lett. 2011;36(7):1122-4. https://doi.org/10.1364/OL.36.001122.

63. Hilligsøe KM, Paulsen HN, Thøgersen J, Keiding SR, Larsen JJ. Initial steps of supercontinuum generation in photonic crystal fibers. J Opt Soc Am B. 2003;20(9):1887-93. https://doi.org/10.1364/JOSAB.20.001887. 
64. Sakamaki K, Nakao M, Naganuma M, Izutsu M. Soliton induced supercontinuum generation in photonic crystal fiber. IEEE J Sel Top Quant. 2004;10(5):876-84. https://doi.org/10.1109/JSTQE.2004.837223.

65. Moeser JT, Wolchover NA, Knight JC, Omenetto FG. Initial dynamics of supercontinuum generation in highly nonlinear photonic crystal fiber. Opt Lett. 2007;32(8):952-4. https://doi.org/10.1364/OL.32.000952.

66. Cheng T, Kanou Y, Asano K, Deng D, Liao M, Matsumoto M, et al. Soliton self-frequency shift and dispersive wave in a hybrid four-hole $\mathrm{AsSe}_{2}-\mathrm{As}_{2} \mathrm{~S}_{5}$ microstructured optical fiber. Appl Phys Lett. 2014;104(12):662.

67. El-Amraoui M, Gadret G, Jules JC, Fatome J, Fortier C, Désévédavy F, et al. Microstructured chalcogenide optical fibers from $\mathrm{As}_{2} \mathrm{~S}_{3}$ glass: towards new IR broadband sources. Opt Express. 2010;18(25):26655-65. https://doi.org/10.1364/OE.18. 026655 .

68. Rudy CW, Marandi A, Vodopyanov KL, Byer RL. Octave-spanning supercontinuum generation in in situ tapered $\mathrm{As}_{2} \mathrm{~S}_{3}$ fiber pumped by a thulium-doped fiber laser. Opt Lett. 2013;38(15):2865-8. https://doi.org/10.1364/OL.38.002865.

69. Duval S, Bernier M, Fortin V, Genest J, Piché M, Vallée R. Femtosecond fiber lasers reach the mid-infrared. Optica. 2015; 2(7):623-6. https://doi.org/10.1364/OPTICA.2.000623.

70. Hudson DD, Antipov S, Li L, Alamgir I, Hu T, Amraoui ME, et al. Toward all-fiber supercontinuum spanning the midinfrared. Optica. 2017;4(10):1163-6. https://doi.org/10.1364/OPTICA.4.001163.

71. Thapa R, Gattass RR, Nguyen V, Chin G, Gibson D, Kim W, et al. Low-loss, robust fusion splicing of silica to chalcogenide fiber for integrated mid-infrared laser technology development. Opt Lett. 2015;40(21):5074-7. https:/doi.org/10.1364/OL.40.005074.

72. Cheng T, Nagasaka K, Tuan TH, Xue X, Matsumoto M, Tezuka H, et al. Mid-infrared supercontinuum generation spanning 2.0 to $15.1 \mu \mathrm{m}$ in a chalcogenide step-index fiber. Opt Lett. 2016;41(9):2117-20. https://doi.org/10.1364/OL.41.002117.

73. Møller U, Yu Y, Kubat I, Petersen CR, Gai X, Brilland L, et al. Multi-milliwatt mid-infrared supercontinuum generation in a suspended core chalcogenide fiber. Opt Express. 2015;23(3):3282-91. https://doi.org/10.1364/OE.23.003282.

74. Petersen CR, Engelsholm RD, Markos C, Brilland L, Caillaud C, Trolès J, et al. Increased mid-infrared supercontinuum bandwidth and average power by tapering large-mode-area chalcogenide photonic crystal fibers. Opt Express. 2017; 25(13):15336-48. https://doi.org/10.1364/OE.25.015336.

75. Kubat I, Petersen CR, Møller UV, Seddon AB, Benson T, Brilland L, et al. Thulium pumped mid-infrared 0.9-9um supercontinuum generation in concatenated fluoride and chalcogenide glass fibers. Opt Express. 2014;22(4):3959-67. https://doi.org/10.1364/OE.22.003959.

76. Petersen CR, Moselund PM, Petersen C, Møller U, Bang O. Spectral-temporal composition matters when cascading supercontinua into the mid-infrared. Opt Express. 2016;24(2):749-58. https://doi.org/10.1364/OE.24.000749.

77. Robichaud LR, Fortin V, Gauthier JC, Châtigny S, Couillard JF, Delarosbil JL, et al. Compact 3-8 $\mu$ m supercontinuum generation in a low-loss $\mathrm{As}_{2} \mathrm{Se}_{3}$ step-index fiber. Opt Lett. 2016;41(20):4605-8. https://doi.org/10.1364/OL.41.004605.

78. Martinez RA, Plant G, Guo K, Janiszewski B, Freeman MJ, Maynard RL, et al. Mid-infrared supercontinuum generation from 1.6 to $>11 \mu \mathrm{m}$ using concatenated step-index fluoride and chalcogenide fibers. Opt Lett. 2018;43(2):296-9. https:// doi.org/10.1364/OL.43.000296.

79. Woyessa G, Kwarkye K, Dasa MK, Petersen CR, Sidharthan R, Chen S, et al. Power stable 1.5-10.5 $\mu$ m cascaded mid-infrared supercontinuum laser without thulium amplifier. Opt Lett. 2021;46(5):1129-32. https://doi.org/10.1364/OL.416123.

80. Venck S, St-Hilaire F, Brilland L, Ghosh AN, Chahal R, Caillaud C, et al. 2-10 um mid-infrared fiber-based supercontinuum laser source: experiment and simulation. Laser Photonics Rev. 2020;14(6):2000011. https://doi.org/10.1002/por.202000011.

81. Petersen CR, Lotz MB, Woyessa G, Ghosh AN, Sylvestre T, Brilland L, et al. Nanoimprinting and tapering of chalcogenide photonic crystal fibers for cascaded supercontinuum generation. Opt Lett. 2019;44(22):5505-8. https:/doi.org/10.1364/OL.44.005505.

82. Robichaud LR, Duval S, Pleau LP, Fortin V, Bah ST, Châtigny S, et al. High-power supercontinuum generation in the mid-infrared pumped by a soliton self-frequency shifted source. Opt Express. 2020;28(1):107-15. https:/doi.org/10.1364/OE.380737.

83. Yin K, Zhang B, Yao J, Yang L, Chen S, Hou J. Highly stable, monolithic, single-mode mid-infrared supercontinuum source based on low-loss fusion spliced silica and fluoride fibers. Opt Lett. 2016;41(5):946-9. https://doi.org/10.1364/ OL.41.000946.

84. Yang $L$, Yan B, Zhao R, Wu D, Xu T, Yang P, et al. Ultra-low fusion splicing loss between silica and ZBLAN fiber for allfiber structured high-power mid-infrared supercontinuum generation. Infrared Phys Techn. 2021;113(103576). https://doi. org/10.1016/j.infrared.2020.103576.

85. Curry RJ, Birtwell SW, Mairaj AK, Feng X, Hewak DW. A study of environmental effects on the attenuation of chalcogenide optical fibre. J Non-Cryst Solids. 2005;351(6):477-81. https://doi.org/10.1016/j.jnoncrysol.2004.12.013.

86. Wang T, Gai X, Wei W, Wang R, Yang Z, Shen X, et al. Systematic Z-scan measurements of the third order nonlinearity of chalcogenide glasses. Opt Mater Express. 2014;4(5):1011-22.

87. Wei W, Wang R, Shen X, Fang L, Luther-Davies B. Correlation between structural and physical properties in Ge-Sb-se glasses. J Phys Chem C. 2013;117(32):16571-6. https://doi.org/10.1021/jp404001h.

88. Ou H, Dai S, Zhang P, Liu Z, Wang X, Chen F, et al. Ultrabroad supercontinuum generated from a highly nonlinear GeSb-se fiber. Opt Lett. 2016;41(14):3201-4. https://doi.org/10.1364/OL.41.003201.

89. Zhang B, Yu Y, Zhai C, Qi S, Wang Y, Yang A, et al. High brightness 2.2-12 $\mu \mathrm{m}$ mid-infrared Supercontinuum generation in a nontoxic Chalcogenide step-index Fiber. J Am Ceram Soc. 2016;99(8):2565-8. https://doi.org/10.1111/jace.14391.

90. Wilhelm AA, Boussard-Plédel C, Coulombier Q, Lucas J, Bureau B, Lucas P. Development of far-infrared-transmitting Te based glasses suitable for carbon dioxide detection and space optics. Adv Mater. 2007;19(22):3796-800. https://doi.org/1 $0.1002 / a d m a .200700823$.

91. Yang Z, Lucas P. Tellurium-based far-infrared transmitting glasses. J Am Ceram Soc. 2009;92(12):2920-3. https://doi.org/1 0.1111/j.1551-2916.2009.03323.x.

92. Danto S, Houizot P, Boussard-Pledel C, Zhang XH, Smektala F, Lucas J. A family of far-infrared-transmitting glasses in the GaGe-Te system for space applications. Adv Funct Mater. 2006;16(14):1847-52. https://doi.org/10.1002/adfm.200500645.

93. Yuan $Y$, Yang P, Peng X, Cao Z, Ding S, Zhang N, et al. Ultrabroadband and coherent mid-infrared supercontinuum generation in all-normal dispersion Te-based chalcogenide all-solid microstructured fiber. J. Opt. Soc. Am. B. 2020;37(2): 227-32. https://doi.org/10.1364/JOSAB.37.000227.

94. Zhang N, Peng X, Wang Y, Dai S, Yuan Y, Su J, et al. Ultrabroadband and coherent mid-infrared supercontinuum generation in Te-based chalcogenide tapered fiber with all-normal dispersion. Opt Express. 2019;27(7):10311-9. https:// doi.org/10.1364/OE.27.010311. 
95. Jiao K, Yao J, Zhao Z, Wang X, Si N, Wang X, et al. Mid-infrared flattened supercontinuum generation in all-normal dispersion tellurium chalcogenide fiber. Opt Express. 2019;27(3):2036-43. https://doi.org/10.1364/OE.27.002036.

96. Zhao Z, Chen P, Wang X, Xue Z, Tian Y, Jiao K, et al. A novel chalcohalide fiber with high nonlinearity and low material zero-dispersion via extrusion. J Am Ceram Soc. 2019;102(9):5172-9. https://doi.org/10.1111/jace.16439.

97. Jiao K, Yao J, Wang $X$, Wang $X$, Zhao Z, Zhang B, et al. 1.2-15.2 $\mu \mathrm{m}$ supercontinuum generation in a low-loss chalcohalide fiber pumped at a deep anomalous-dispersion region. Opt Lett. 2019;44(22):5545-8. https://doi.org/10.13 64/OL.44.005545.

98. Zhong M, Liang X, Jiao K, Wang X, Si N, Xu T, et al. Low-loss chalcogenide fiber prepared by double peeled-off extrusion. J Lightwave Technol. 2020;38(16):4533-9. https://doi.org/10.1109/JLT.2020.2992291.

99. Rothman LS, Gordon IE, Babikov Y, Barbe A, Benner DC, Bernath PF, et al. The HITRAN2012 molecular spectroscopic database. J Quant Spectrosc Radiat Transf. 2013;130:4-50. https://doi.org/10.1016/j.jqsrt.2013.07.002.

100. Amiot C, Ryczkowski P, Aalto A, Toivonen J, Genty G. Multi-component gas detection in the mid-IR. SPIE Newsroom. 2015. https://doi.org/10.1117/2.1201510.006199

101. Kilgus J, Duswald K, Langer G, Brandstetter M. Mid-infrared standoff spectroscopy using a supercontinuum laser with compact Fabry-Pérot filter spectrometers. Appl Spectrosc. 2018;72(4):634-42. https://doi.org/10.1177/0003702817746696.

102. Kumar M, Islam MN, Terry FL, Freeman MJ, Chan A, Neelakandan M, et al. Stand-off detection of solid targets with diffuse reflection spectroscopy using a high-power mid-infrared supercontinuum source. Appl Opt. 2012;51(15):2794807. https://doi.org/10.1364/AO.51.002794.

\section{Publisher's Note}

Springer Nature remains neutral with regard to jurisdictional claims in published maps and institutional affiliations.

Submit your manuscript to a SpringerOpen ${ }^{\circ}$ journal and benefit from:

- Convenient online submission

- Rigorous peer review

- Open access: articles freely available online

- High visibility within the field

- Retaining the copyright to your article

Submit your next manuscript at $\boldsymbol{\nabla}$ springeropen.com 